The Decline, Rebound, and Further Rise in SNAP Enrollment: Disentangling Business Cycle Fluctuations and Policy Changes Faculty Research Working Paper Series

\title{
Peter Ganong
}

Harvard University, Faculty of Arts and Sciences and NBER

Jeffrey B. Liebman

Harvard Kennedy School and NBER

\section{October 2013 RWP13-037}

Visit the HKS Faculty Research Working Paper Series at:

http://web.hks.harvard.edu/publications

The views expressed in the HKS Faculty Research Working Paper Series are those of the author(s) and do not necessarily reflect those of the John F. Kennedy School of Government or of Harvard University. Faculty Research Working Papers have not undergone formal review and approval. Such papers are included in this series to elicit feedback and to encourage debate on important public policy challenges. Copyright belongs to the author(s). Papers may be downloaded for personal use only. 
NBER WORKING PAPER SERIES

\author{
THE DECLINE, REBOUND, AND FURTHER RISE IN SNAP ENROLLMENT: \\ DISENTANGLING BUSINESS CYCLE FLUCTUATIONS AND POLICY CHANGES \\ Peter Ganong \\ Jeffrey B. Liebman \\ Working Paper 19363 \\ http://www.nber.org/papers/w19363
}
NATIONAL BUREAU OF ECONOMIC RESEARCH
1050 Massachusetts Avenue
Cambridge, MA 02138

August 2013

We thank Michael DePiro at USDA for providing us with county-level SNAP enrollment. We thank John Coglianese and Wayne Sandholtz for excellent research assistance and Gabe Chodorow-Reich, Ben Hebert, Simon Jäger, Larry Katz, John Kirlin, Josh Leftin, Bruce Meyer, Mikkel Plagborg-Møller, and James Ziliak for helpful comments. Ganong gratefully acknowledges funding from the NBER Pre-Doctoral Fellowship in Aging and Health. The views expressed herein are those of the authors and do not necessarily reflect the views of the National Bureau of Economic Research.

NBER working papers are circulated for discussion and comment purposes. They have not been peerreviewed or been subject to the review by the NBER Board of Directors that accompanies official NBER publications.

(C) 2013 by Peter Ganong and Jeffrey B. Liebman. All rights reserved. Short sections of text, not to exceed two paragraphs, may be quoted without explicit permission provided that full credit, including (C) notice, is given to the source. 
The Decline, Rebound, and Further Rise in SNAP Enrollment: Disentangling Business Cycle

Fluctuations and Policy Changes

Peter Ganong and Jeffrey B. Liebman

NBER Working Paper No. 19363

August 2013

JEL No. E24,E62,H53,I38

\begin{abstract}
Approximately 1-in-7 people and 1-in-4 children received benefits from the US Supplemental Nutrition Assistance Program (SNAP) in July 2011, both all-time highs. We analyze changes in SNAP take-up over the past two decades. From 1994 to 2001, coincident with welfare reform, take-up fell from 75\% to $54 \%$ of eligible people. The take-up rate then rebounded, and, following several policy changes to improve program access, stabilized at $69 \%$ in 2007 . Finally, take-up and enrollment rose dramatically in the Great Recession, with take-up reaching $87 \%$ in 2011 . We find that changes in local unemployment can explain at least two-thirds of the increase in enrollment from 2007 to 2011. Increased state adoption of relaxed income and asset thresholds and temporary changes in program rules for childless adults explain $18 \%$ of the increase. Total SNAP spending today is $6 \%$ higher than it would be without these increases in eligibility. The recession-era increase in benefit levels is also likely to have increased enrollment.
\end{abstract}

Peter Ganong

Harvard University

ganong@fas.harvard.edu

Jeffrey B. Liebman

John F. Kennedy School of Government

Harvard University

79 JFK Street

Cambridge, MA 02138

and NBER

jeffrey_liebman@harvard.edu 


\section{Introduction}

In July 2011, 45.3 million people were enrolled in the Supplemental Nutrition Assistance Program (SNAP), fifteen percent of the US population. ${ }^{2}$ This is a sharp increase from 26.6 million and nine percent of the population in July 2007. There has been considerable debate about the growth in SNAP enrollment in the aftermath of the recession. Researchers at the US Department of Agriculture (Hanson and Oliveira (2012), USDA) analyzed national annual time series evidence and concluded that the increase in unemployment rates can explain most of the growth, while Mulligan (2012) finds that changes in SNAP policies played a central role. In this paper, we attempt to explain trends in SNAP enrollment over the past twenty years, and bring new data to bear on the debate over current SNAP enrollment.

Figure 1 shows estimates of the percent of the population enrolled in SNAP and the SNAP take-up rate. Because household income is volatile and not all the information needed to establish eligibility is available in household surveys, it is quite difficult to estimate the number of people who are eligible for SNAP at a point in time. Mathematica Policy Research (Eslami et al. (2012)) produces estimates of eligibility using data on annual income in the March Current Population Survey, combined with adjustment procedures for a variety of program requirements including legal residency, asset tests, and work requirements. ${ }^{3}$ Changes in estimated take-up closely track changes in the percent of the population enrolled in SNAP. Take-up fell from 75\% in 1994 to $54 \%$ in 2001 . It then rebounded up to $69 \%$ in 2006 . Enrollment and takeup then remained stable through 2008. Finally, take-up rose significantly in

\footnotetext{
${ }^{2}$ The 2008 Farm Bill changed the program name from the "Food Stamp Program" to the "Supplemental Nutrition Assistance Program." We use SNAP throughout the paper to refer to this program, regardless of time period.

${ }^{3}$ Cunnyngham and Smith (2013) provide a detailed description of the methodology for 2010. Mathematica reports do not provide a consistent time series because of changes over time in their methodology. We attempt to construct a consistent time series by splicing together the Mathematica estimates. See notes to Figure 1 for details on how we construct a consistent time series. Another challenge to producing an estimate of take-up among eligible individuals is that some recipients may be ineligible and estimates of the fraction of recipients who are ineligible are imperfect.
} 
the recent recession, reaching $87 \%$ in 2011 . We use these inflection points in the take-up rate to organize our analysis into three periods: Welfare Reform, Bush-Era Modernization, and the Great Recession.

In 1992, Oregon was the first state approved for a major waiver from the federal government to modify its cash assistance program. ${ }^{4}$ Over the next few years, 36 additional states received waivers, culminating in the passage of federal welfare reform in 1996. Cash assistance receipt declined dramatically, from 14.0 million individuals in 1994 to 5.6 million in 2000; SNAP receipt among families with children, as well as among adults who were newly subjected to SNAP time limits by federal welfare reform, declined concurrently. We demonstrate that states with bigger declines in cash assistance receipt had bigger declines in SNAP receipt among families with children. We further show that the change in SNAP enrollment for families with single mothers over this period can be decomposed into to two equally important factors. First, there was a decrease in the number of eligible individuals because of rising incomes. Second, among eligible individuals, there was an increase in the fraction of individuals with significant earnings and there has historically been a much lower take-up rate of SNAP benefits among people who are working.

Beginning in 2001, with encouragement from USDA, states implemented a series of policy changes designed to improve access to SNAP for working families. States relaxed vehicle ownership rules, redesigned income reporting requirements, and promoted phone interviews in lieu of face-to-face interviews for establishing and maintaining eligibility. Enrollment rose, even as the unemployment rate was falling, and the program became more dynamic, with more people entering and exiting SNAP. In addition, we find evidence of a "bounceback" from welfare reform - states with bigger declines in cash assistance in the 1990's experienced bigger increases in SNAP receipt several years later.

Once the Great Recession began, SNAP enrollment increased rapidly. Our

\footnotetext{
${ }^{4}$ We use the term "cash assistance" to refer to both Aid to Families with Dependent Children and Transitional Aid to Needy Families.
} 
research assesses the extent to which SNAP enrollment should be viewed as an "automatic stabilizer," rising directly in response to unemployment, or as a deliberate fiscal policy response to the recession. There is a wide consensus among economists that automatic stabilizers are good policy for responding to business cycle changes, while there is disagreement over the usefulness of discretionary fiscal policy. ${ }^{5}$

We model the relationship between unemployment and SNAP enrollment. Using family-level data from the Survey of Income and Program Participation (SIPP), we estimate that changes in unemployment duration alone can explain about half of the increase in SNAP enrollment from 2007 to 2011. Next, using county-level data, we find that local area unemployment can explain between $71 \%$ and $98 \%$ of the increase in SNAP enrollment, depending on the specification. ${ }^{6}$

We examine in detail the eligibility expansions and policy changes which may also have increased SNAP enrollment during the recession years. We find that states' adoption of relaxed income and asset limits ("Broad Based Categorical Eligibility") accounts for $8 \%$ of the increase in enrollment over this period. Another feature of SNAP is that program rules for Able-Bodied Adults Without Dependents (ABAWDs) are temporarily relaxed in places with high unemployment. Expanded eligibility for ABAWDs during the recession can explain $10 \%$ of the increase in enrollment. We repeat the exercise for spending and find that $\mathrm{BBCE}$ and $\mathrm{ABAWD}$ changes are responsible for $3 \%$ and $9 \%$

\footnotetext{
${ }^{5}$ See Auerbach (2003) for a critique of fiscal policy responses and Blinder (2006) for a response to the critics of fiscal policy. Nevertheless, both view automatic stabilizers favorably. Blanchard et al. (2010) distinguish between two kinds of automatic stabilizers - progressive tax-and-transfer schedules, which have permanent fiscal costs and incentive consequences, and temporary policies which respond to unemployment, which they view as "more promising." Blundell and Pistaferri (2003) and Gundersen and Ziliak (2003) estimate the consumption insurance provided by SNAP, which fits Blanchard's first type of automatic stabilizer, while this paper highlights the response of SNAP to unemployment, consistent with Blanchard's second type of stabilizer. In other recent work, McKay and Reis (2013) argue that SNAP is particularly effective as an automatic stabilizer.

${ }^{6}$ Bitler and Hoynes (2013) use state-level data to analyze changes in several different transfer programs over the business cycle, and report that the response of SNAP and unemployment insurance during the Great Recession was in line with historical patterns.
} 
of the increase in spending, respectively. Finally, the temporary increase in SNAP benefits in the Recovery Act may have raised take-up, although we are unable to quantify its impact.

Section 2 provides an overview of program rules and enrollment trends. Section 3 describes changes in participation from 1991 to 2001, the period surrounding welfare reform. Section 4 describes changes from 2001 to 2007, when the Bush administration made several changes to the program. Section 5 analyzes the increase in enrollment during the Great Recession. Section 6 concludes.

\section{Program Overview}

\subsection{Program Description}

SNAP helps low-income people buy food. A household unit is people who "purchase and prepare food together." Eligibility is typically determined by three tests:

- gross income test - household income must be less than $130 \%$ of the poverty line (in FY2013, $130 \%$ of poverty is $\$ 1,211 /$ month for one person and $\$ 2,498 /$ month for four people).

- net income test - household income minus deductions must be less than $100 \%$ of the poverty line. ${ }^{7}$

- asset test - assets must be less than $\$ 2,000$, excluding the recipient's home and retirement accounts.

\footnotetext{
${ }^{7}$ There is a standard deduction of $\$ 149$ for households with 1 to 3 members (with higher amounts for larger households), a $20 \%$ earned income deduction, a medical expense deduction for households with elderly or disabled members, a child care deduction, and a deduction for households with very high shelter costs. http://www.massresources.org/snapfinancial-eligibility.html offers a clear description of these rules.
} 
Households with a disabled person or a member whose age is 60 or above need to pass only the net income test (not gross income), and face a less stringent asset threshold of $\$ 3,250$. Able-Bodied Adults Without Dependents who are working less than half time or do not meet certain work requirements are limited to receiving benefits for 3-months out of each 36-month period.

Program applicants must participate in an interview and provide documentation of legal residency, income, and expenses. Then, recipients need to complete a recertification on a recurring basis every 6 to 24 months.

Households receive an electronic benefit transfer card, which can be used to purchase food at supermarkets, grocery stores, and convenience stores. About $84 \%$ of benefits are spent at supermarkets (Castner and Henke (2011)). A household's benefit is equal to the maximum benefit, minus $30 \%$ of its net income. In fiscal year 2011, the maximum monthly benefit was $\$ 200$ for one person (mean $\$ 146$ ) and $\$ 668$ for four people (mean $\$ 482$ ).

States administer the program, determining eligibility and issuing benefits. The cost of benefits is paid entirely by the federal government, through USDA. Administrative costs are split between the state and federal government. Each year, about 50,000 active cases are randomly selected for audits through the Quality Control (QC) system, and the results are used to calculate a state's payment error rate. In FY2011, the official national overpayment error rate was $3.0 \%$, and the underpayment error rate was $0.8 \%$. States with persistently high error rates incur financial penalties.

Economists have done substantial research on the impacts of SNAP on recipients. A recent series of papers by Hilary Hoynes, Diane Whitmore Schanzenbach, and coauthors uses the county-level rollout of SNAP to study the program's impacts. Almond et al. (2011) find that program exposure raised birth weights, and Hoynes and Schanzenbach (2009) find that the program raised food expenditures. Evidently, program recipients face significant cash constraints, with lower caloric intake at the end of the monthly benefit 
cycle (Shapiro (2005)). Hastings and Washington (2010) show that supermarket prices respond modestly to changes in demand by benefit recipients; the magnitude of price responses is likely to be small because recipients shop alongside non-recipients.

\subsection{Methodology for Constructing Time series Patterns in Enrollment and Flows}

Mathematica Policy Research uses the QC data to construct a public use file each year that is representative of the national SNAP caseload. ${ }^{8}$

Figure 2 shows trends in SNAP receipt by household type using the QC data. We divide households into three mutually-exclusive groups:

1. "Families with Children" - household has at least one child (under age 18).

2. "Adults" - household has no children and at least one non-senior adult (ages 18-59).

3. "Seniors" - all household members are seniors (at least age 60).

In the top panel, we show the size of each group on SNAP as a share of the total US population. In 1991, families with children accounted for $84 \%$ of SNAP recipients, households with adults (and no children) were $11 \%$ of recipients, and households with seniors were $5 \%$ of recipients. To better highlight changes in SNAP receipt by household type, we construct an index for enrollment relative to 1991 levels shown in the bottom panel. To control for changes

\footnotetext{
${ }^{8}$ Files from fiscal year 1996 forward are posted at http://hostm142.mathematicampr.com/fns/. Leftin et al. (2012) provides documentation for the most recent file. We limit our analysis to the fifty states plus D.C. Throughout our analysis, we use variables fywgt for household weight to match national caseloads and certhhsz for the number of post-audit household members.
} 
in demographic structure, we use the March Current Population Survey to estimate the total US population in each household type $j$ in each year $t$. We calculate

$$
\text { EnrollmentIndex }_{j t}=\frac{S N A P_{j t}}{\operatorname{Pop}_{j t}} / \frac{S N A P_{j, 1991}}{\operatorname{Pop}_{j, 1991}}
$$

The QC files can also be used to estimate flows into and out of SNAP, as shown in Figure 3. We flag a case as a new entrant if the most recent action on the case was a certification, rather than a recertification (actntype==1) and the most recent certification occurred in the previous three months (lastcert<=2). ${ }^{9}$ We observe total participants $S N A P_{t}, S N A P_{t-1}$, and enter ${ }_{t}$ in the QC files, and calculate exit using the statistical identity:

$$
S N A P_{t}-S N A P_{t-1}=\text { enter }_{t}-\text { exit }_{t}
$$

In Figure 3, we plot entry and exit as a share of the US population. ${ }^{10}$

\section{Welfare Reform, 1991-2001}

In this section, we analyze changes in SNAP from 1991 to 2001, with particular attention to the role of welfare reform in causing people to leave SNAP. We use the QC files and the SIPP to show that SNAP receipt declined more in demographic groups most affected by welfare reform, in states where cash assistance caseloads dropped the most, and for people receiving cash assistance at the time of the 1996 welfare reform legislation.

\footnotetext{
${ }^{9}$ Before FY95, lastcert is often missing, and we instead identify entrants using (actntype=1) combined with the date the case was opened (rcntopen). For 1995, when both variables are available, we find that using the most recent action date yields a quarterly entrance rate of $15 \%$ and using the case opening date yields a quarterly entrance rate of $19 \%$.

${ }^{10}$ In Appendix Figure 1, we show entry rates - entrances as share of the unenrolled $\left(\right.$ EntryRate $_{t}=$ enter $_{t} /\left(\right.$ pop $\left.\left._{t}-S N A P_{t}\right)\right)$ and exit rates - exits as a share of enrollment $\left(\right.$ ExitRate $_{t}=$ exit $\left._{t} / S N A P_{t}\right)$. These rates have the attractive feature that they are scaled by the exposed population and therefore can allow more natural comparisons of transition rates across time periods with widely varying SNAP participation rates.
} 
From 1993 to 1999, the number of cash assistance recipients in the US fell dramatically. An unusually strong labor market and expansions of the Earned Income Tax Credit led single mothers to transition from cash assistance receipt to work (Meyer and Rosenbaum (2001)). Welfare reform played an important role as well: the first major waivers for changes in state welfare policy were given in 1992. By the time President Clinton signed the Personal Responsibility and Work Opportunity Act (PRWORA) in 1996, 37 states had already received waivers. Currie and Grogger (2001) estimate a state-level model and find that the improving economy can explain about $30 \%$ and welfare reform can explain about 20\% of the decrease in SNAP receipt from 1993 to 1998.

Both panels of Figure 2 show that SNAP receipt fell relative to the overall population beginning in 1993, with the rate of decline increasing after welfare reform in 1996. The new law also revoked SNAP eligibility for many legal immigrants. ${ }^{11}$ Families with children, who were leaving cash assistance, show the biggest declines in SNAP receipt. Adults, some of whom were newly subjected by PRWORA to a 3-months-out-of-36 time limit for SNAP receipt, also show large declines. Seniors, who presumably were least affected by welfare reform, show the smallest declines. Figure 3 shows that through 1993, entrances exceed exits, and caseloads were rising. After this point, as the economy recovered and states began experimenting with welfare reform, exits substantially exceed entrances, and caseloads begin to fall. As cash assistance recipients transitioned to work, we calculate in the QC files that the share of people in SNAP families with children reporting earned income rose from $30 \%$ to $45 \%$.

State-level evidence points to a link between the intensity of welfare reform and SNAP receipt. Because the timing of welfare reform varied across states,

${ }^{11}$ The number of eligible noncitizens fell from 2.71 million in 1994 to 1.33 million in 2000, and SNAP receipt fell even more sharply, from 1.81 million to 0.59 million, over the same period (Cunnyngham (2002)). Borjas (2004) uses this policy change to study the effect of public assistance on food insecurity and finds that a 10 percentage point reduction in the fraction of the population that receives public assistance increases the fraction of foodinsecure households by about 5 percentage points. 
we define $t($ peak) as the year in which a state $j$ reached its maximum number of cash assistance recipients. For 41 states, this occurred between 1992 and 1994. Cash $_{j, t(p e a k)}$ is the number of people receiving cash assistance in the peak year in state $j$. We measure the intensity of welfare reform as the change from the peak to five years later $\left(\log \operatorname{Cash}_{j, t(p e a k)+5}-\log \operatorname{Cash}_{j, t(p e a k)}\right)$ and compare this to the change in SNAP receipt over the same time period. We regress

$\log S N A P_{j, t(p e a k)+5}-\log S N A P_{j, t(p e a k)}=\alpha+\beta\left(\log \operatorname{Cash}_{j, t(p e a k)+5}-\log \operatorname{Cash}_{j, t(p e a k)}\right)+\varepsilon_{j t(p e a k)}$

The top panel of Figure 4 shows a strong, statistically significant correlation: a 10 log point decrease in cash assistance receipt is associated with about a 3 log point decrease in SNAP receipt among families with children. ${ }^{12}$ This suggests that at the state level, the intensity of welfare reform was correlated with changes in SNAP receipt. Cash assistance receipt fell on average by 65 log points in the five years after a state's peak, and SNAP receipt fell by an average of $34 \mathrm{log}$ points, so the change in SNAP receipt implied by the cross-sectional coefficient $\left(0.29^{*} 65=18.9\right)$ is about half of the observed drop in SNAP receipt. This means that above and beyond any changes in the national economy or national policies, changes in state-level conditions were important in explaining changes in SNAP receipt. ${ }^{13}$

\footnotetext{
${ }^{12}$ An alternative specification uses a common time period, of 1994 to 1999. We drop Idaho and Wyoming, which are extreme outliers in their change in cash assistance. Here, we find a coefficient of 0.12 , which is statistically significant at a $10 \%$ level. We find this specification less attractive because it does not account for heterogeneity in when states began changing their welfare programs, as discussed above.

${ }^{13}$ Two pieces of evidence suggest that the state-level correlation between welfare reform and SNAP receipt is not simply the result of state economic conditions affecting caseloads for both transfer programs. First, our welfare reform measure has only a weak correlation with changes in the contemporaneous unemployment rate. A 10 log point decrease in caseloads from peak is associated with an additional decrease of 0.05 percentage points in the state unemployment rate (not statistically significant). Adding the state unemployment rate as a regressor in the regression specified in equation 3 has barely any impact on the coefficent on the change in cash assistance. Because measurement error in the state unemployment rate could bias downward the impact of the unemployment rate in the regression, we find the more direct evidence from regressing the unemployment rate on the change in caseloads to be more informative. Second, when we regress changes in cash assistance caseloads on changes
} 
To further explore the connection between welfare reform and SNAP receipt, we use the March CPS together with the QC files to study SNAP enrollment by single mothers with children from 1993 through 1999. In particular, we use the CPS data to distinguish among three explanations for the decline in SNAP receipt: (1) mothers increased their employment and were no longer eligible, (2) mothers increased their employment, were still eligible, but because SNAP take-up rates are lower among those with earnings, their SNAP participation fell, and (3) changes in public assistance administrative practices or individual preferences reduced take-up among people with a given set of characteristics. ${ }^{14}$

First, we divide the sample of single mothers in the CPS by whether or not their income was below $130 \%$ of poverty each year - suggesting whether they were likely to be eligible for SNAP. We then sub-divide the likely-eligible sample into four groups: "Work Only", "Cash Assistance Only", "Work and Cash", or "Neither Work Nor Cash". We define a family as "working" if they have annual earnings equal to at least $25 \%$ of the annual poverty line and as "receiving cash assistance" if they report assistance equal to at least $10 \%$ of the annual poverty line. The proportion of people in each group is shown in the top panel of Appendix Table 1. We see a decline in the share of single mothers who are likely to be eligible for SNAP from $63 \%$ to $53 \%$. Among that pool of likely eligibles, we see a sharp decrease in the share receiving only cash assistance. This is offset by a large increase in the share of single mothers only working, as well as an increase in the share who are neither working nor receiving cash assistance.

Next, we calculate the number of SNAP recipients in each of these four cells using data from the QC. As a secondary measure, we also construct estimates in SNAP receipt for adults and seniors - populations that were less affected by state-level welfare reform activities - we find a smaller and statistically insignificant coefficient. This is evidence that the welfare reform variable reflects state-level policy changes, and not just changes in the state's labor market situation.

${ }^{14}$ Narrative accounts of welfare reform implementation suggest that when people left cash assistance for work they often did not realize (and welfare offices made little effort to tell them) that they remained eligible for SNAP (Government Accountability Office (1999)). 
of the number of SNAP recipients in each cell from the CPS, even though the CPS measure suffers from significant underreporting. These estimates are presented in the second and third panels of Appendix Table 1.

The bottom two panels of Appendix Table 1 also report ratios within each cell of QC recipient totals to CPS population totals and of CPS recipient totals to CPS population totals. Computing the ratio with the $\mathrm{QC}$ data in the numerator and CPS data in the denominator gives us a number analogous to a take-up rate. Such a comparison is likely to be imperfect because the QC files are based on monthly data, while the CPS is based on annual interview data, and because cash assistance receipt for single mothers is underreported in the CPS. In particular, there are more single moms in the QC data with Cash Only than there are in the CPS and the ratio is not constrained to be below $1{ }^{15}$ Nevertheless, such a comparison is useful for examining trends over time. The ratio is highest for the Cash Only group, with an average value of 1.53, and lowest for the Work Only group, with an average value of 0.49 . Notably, all four ratios are fairly stable over this time period. The ratio for the Work and Cash group shows evidence of an increase, but this is the smallest group in absolute magnitude and is therefore most likely to have imprecise ratio estimates. CPS-based results are similar. Within each cell, there is very little change over time in the ratio of SNAP recipients to SNAP-eligible families.

These take-up ratios allow for a unique decomposition of changes in SNAP receipt, first by changes in income eligibility, and then, among income-eligible individuals, by changes in work and cash assistance status.

$$
S N A P_{t+6}-S N A P_{t}=\Delta E l i g * T a k e U p_{t}+\Delta T a k e U p * E_{l i g} g_{t+6}
$$

\footnotetext{
${ }^{15}$ This comparison is made more difficult because, as documented by Meyer et al. (2009), the underreporting of cash assistance in the CPS is rising during this period. Interpreting results from changes in this ratio as changes in take-up requires an assumption that reporting rates for cash assistance are constant. The ratio of the administrative monthly enrollment total from HHS to the CPS total using our method falls from 104\% in 1993 to $87 \%$ in 1999. We rescale our cells each year to match changes in this aggregate reporting ratio. Effectively, this assumes that there is no differential reporting of earnings in the CPS among cash assistance recipients as compared to non-recipients.
} 


$$
\Delta \text { TakeUp }=\sum_{j} \Delta \text { WorkCash }_{j} * \text { TakeUp }_{j t}+\Delta \text { TakeUp }_{j} * \text { WorkCash }_{j, t+6}
$$

Table 1 shows the results of this decomposition. The first column shows our preferred QC-based estimates. Overall, of the 4.4 million person decrease in SNAP receipt among people in families headed by single mother, about half (2.18 million) is due to decreases in eligibility, holding take-up fixed. The rest of the decrease is due to a shift among people who remained eligible from the high take-up category of only receiving cash assistance to the two lower-take up categories of work only and neither work nor cash assistance. The results with the CPS-based measure of SNAP receipt are similar. Changes in take-up ratios within each cell do not play an important role. In other words, in terms of the theories outlined on the previous page, we find evidence consistent with theories (1) and (2), but not theory (3). Whether policy makers intended to have families who remained income eligible lose SNAP receipt when they left cash assistance is unclear.

\section{Bush-Era Modernization, 2001-2007}

The national SNAP take-up rate reached a low point in 2001, with $54 \%$ of eligible individudals receiving benefits. It then began a steady march upward to $69 \%$ in 2006 and 2007. Eligibility rose from 31.2 million in 2001 to 34.4 million in 2002, due largely to changes in vehicle rules, and then roughly kept pace with population growth to reach 37.1 million people in 2007 (Eslami et al. (2012)). ${ }^{16}$ Meanwhile, SNAP enrollment rose from 17.5 million in July 2001 to 26.6 million in July 2007. Two factors can explain most of the increase in take-up during this period: policy changes intended to improve access to SNAP for working families and a bounceback from welfare reform.

Under the Bush administration, led by Under Secretary Eric Bost, there were several policy changes, designed in particular to make it easier to combine work and SNAP receipt. In 2001, Bost testified before Congress:

\footnotetext{
${ }^{16}$ See Table 1 of Cunnyngham (2002) for estimates of the contribution of vehicle rules changes to 2002 eligibility estimates.
} 
Concerns have grown that the program's administrative burden and complexity are hampering its performance in the post-welfare reform environment. There is growing recognition that the complexity of program requirements - often the result of desires to target benefits more precisely - may cause error and deter participation among people eligible for benefits... These burdens are particularly significant for the working families that comprise an increasing portion of the Food Stamp caseload. Caseworkers are often expected to anticipate changes in their income and expenses a difficult and error-prone task, especially for working poor households whose incomes fluctuate... (Bost (2001))

Most of these policy changes were implemented by giving states waivers from program rules, allowing states to verify eligiblity in new ways. For example, states were give permisson to set up call centers and conduct eligibility and recertification interviews over the phone, making it easier for people who are not available to come into a welfare office during work hours to meet program requirements. Similarly, most states reduced the frequency at which they collected updated income data from recipients and recalculated benefits. Reduced income reporting requirements eased participation for low-income households with volatile earnings.

During this period, SNAP receipt rose for all three types of families, as shown in Figure 2. Of particular note is that program receipt became more dynamic, as shown in Figure 3. In 2000, 1.1\% of the US population was entering and exiting SNAP each quarter, as shown in Figure 3. By 2005, $1.5 \%$ of people were entering and exiting each quarter. Because, as Bost says, families with marginal labor force attachment will experience greater changes in eligibility from month to month, improved access for working families would likely manifest itself with increased entrances and exits. Acs and Schwabish (2011) find using microdata from the SIPP that "Recipients who combine food stamps and work in the same four month period are substantially more likely 
to exit the program and exit the program with earnings than adults who do not mix food stamps and work." In the QC files, SNAP enrollment rose both for families with earnings and for families without earnings. ${ }^{17}$

In Table 2, we show the number of states implementing various policies by year, as reported in the SNAP Policy Database. ${ }^{18}$ Three particularly important changes were to income reporting, recertification periods, and interview structure:

- Simplified Reporting - Under default program rules in 2001, SNAP recipients were required to report any change in income. USDA first gave states waivers requiring the reporting of only significant income changes (e.g. a $\$ 100$ change in monthly income). This culminated in simplified reporting, where SNAP recipients were required to report income changes between six-month recertification dates only if the income changes made them ineligible for benefits. By 2007, 47 states had adopted simplified reporting.

- Recertification Lengths - After welfare reform, many states had implemented recertifications of three months or shorter. Longer intervals between recertifications for people with earnings reduce the cost of participating in the program on an annual basis. Kabbani and Wilde (2003) and Ribar et al. (2008) study the impact of recertification intervals on SNAP take-up. In 2001, 25 states were using certification intervals of three months or less for many people with earnings, but by 2007, all 50 states and DC had stopped using such short intervals.

\footnotetext{
${ }^{17}$ An increase in SNAP receipt among families without earnings may occur in conjunction with greater labor market activity by low-income families, if families with fluctuating earnings enroll only when they have zero earnings, but not when they have positive earnings. It is also possible that attempts to make SNAP participation easier for eligible households with earnings spilled over into a general effort to make participation easier for eligible households either through changes in administrative behavior or through changes in awareness about program eligibility.

${ }^{18}$ These data are available at http://www.ers.usda.gov/data-products/snap-policydatabase.aspx
} 
- Interview Format - Under default program rules in 2001, SNAP applicants were required to do a face-to-face interview to establish eligibility and for every recertification, unless the household had demonstrated difficulty with completing such an interview. Over time, USDA gave states waivers allowing phone interviews, first for recertification, and then later for initial certifications. By 2007, 22 states had received a waiver of the face-to-face requirement for recertifications.

Other innovations during this period include the establishment of call centers (20 states by 2007), online applications (14 states by 2007), and the Supplemental Security Income Combined Application Project (SSI CAP), which eased enrollment procedures for SSI recipients(12 states by 2007). ${ }^{19}$

In addition, there were rule changes which may have raised enrollment by expanding eligibility, but should not directly have affected estimated take-up: ${ }^{20}$

- Vehicle Exemptions - Under default program rules in 2001, the value of a family's vehicles above an exemption counted towards the asset test. ${ }^{21}$ Over time, states were given flexibility to revise their vehicle policies. By 2007, 46 states exempted at least one vehicle completely from the asset test.

- Legal Immigrants - The 2002 Farm Bill reinstated eligibility for some legal immigrants whose eligibility had been revoked in PRWORA. By 2007, about 0.94 million legal immigrants were receiving SNAP, an increase from 0.59 million in 2000 (Leftin and Wolkwitz (2009)).

\footnotetext{
${ }^{19}$ Dickert-Conlin et al. (2011) analyze the effect of radio ads and Schwabish (2012) analyzes the effect of online applications.

${ }^{20}$ Leftin et al. (2012), and its counterparts for prior years, adjust the number of eligibles in response to changes in rules for vehicles and legal immigrants. They drop recipients eligible through BBCE from both the numerator and denominator of their calculations.

${ }^{21}$ For example, the exemption threshold was $\$ 4,650$ in 2003.
} 
- Broad-Based Categorical Eligibility (BBCE) $)^{22}$ - Under default program rules, eligibility involves a gross income test, a net income test, and an asset test. BBCE allowed states to eliminate the net income and asset tests, and also to raise the threshold for the gross income test, up to $200 \%$ of poverty. However, states still must set benefits as the maximum benefit minus $30 \%$ of net income. For example, in 2013, a household with four members and net income at $100 \%$ of poverty would receive a monthly benefit of $\$ 92$. Put another way, four-member households with net income of $116 \%$ of poverty or higher would not receive any benefits. This benefit calculation rule sharply limits the scope of the eligibility expansion; the group most affected is those with substantially higher gross incomes than net incomes, such as fathers paying child support. By 2007, 13 states had implemented some form of BBCE. We analyze $\mathrm{BBCE}$ in detail in Section 5.3 and find little new enrollment due to BBCE.

We regress each of the state-level policies described above on take-up. Empirically, it is difficult to isolate the effect of each policy separately with statistical precision, so we analyze each policy separately. Using estimates of the SNAP take-up rate each year by state (see Cunnyngham et al. (2013) for the most recent estimates), with $j$ indexing states and $t$ indexing years, we use the specification

$$
\text { Take }-u p_{j t}=\alpha+\beta \text { Policy } j+\eta_{j}+\varphi_{t}+\varepsilon_{j t}
$$

with $\eta_{j}$ state fixed effect and $\varphi_{t}$ year fixed effect. Two caveats are in order. First, even though policies and take-up vary at the state-year level, there is substantial measurement error in policy adoption. ${ }^{23}$ Second, our estimates do

\footnotetext{
22"Broad-Based Categorical Eligibility" is used to distinguish this new policy from a longstanding "Categorical Eligibility" policy, which made people already receiving cash assistance automatically eligible for SNAP.

${ }^{23}$ For example, Trippe and Gillooly (2010) and Government Accountability Office (2012) disagree on the date of $\mathrm{BBCE}$ adoption for 7 states.
} 
not identify the causal impact of these specific policies, because their adoption may be markers for other state-level policy changes.

We report results in Figure 5 and Appendix Table 2. Only the coefficients on simplified reporting and short recertifications are statistically significant. Finally, we construct an omnibus summary index of all eight policies. The coefficient on this index implies that switching from the most stringent policies to the most lenient policies raises the take-up rate by a statistically significant 9.1 percentage points, from a sample mean of 65.2 percent.

We also consider an alternative specification with the percent of population on SNAP $\left(S N A P_{j t} / P_{o p} p_{j t}\right)$ as the dependent variable in equation 6 . Here, we find that BBCE, simplified reporting, call centers, and ending short recertifications have a significant and positive effect on enrollment. ${ }^{24}$ Using the summary index, switching to all of the new policies implies a 2.5 percentage point increase in a state's population receiving SNAP, from a sample mean of 9.0 percent, and this estimate is statistically significant.

We can use these coefficients to estimate the impact of policy changes on aggregate takeup and enrollment. The mean for the summary index rose by 0.42 from 2001 to 2007. Using our takeup regression, this implies an increase in take-up of 3.8 percentage points, one-fourth of the increase in take-up during this period. Alternatively, using our enrollment estimates, this implies an increase in enrollment of 1.0 percentage points, or about one-third of the increase in the enrollment during this period. Given the measurement error regarding the timing of implementation, these estimates are likely to be a lower bound on the impact of state-level policy changes on SNAP take-up during this period. ${ }^{25}$

\footnotetext{
${ }^{24}$ An extensive literature estimates the effect of state SNAP policies on enrollment rates. Most papers find insignificant coefficients for most policies. Klerman and Danielson (2011), Mabli and Ferrerosa (2010), and Mabli et al. (2009) report that a state's adoption of BBCE had a statistically significant impact on enrollment raising it by $6 \%$ and simplified reporting raised enrollment by about a statistically significant $4 \%$. These estimates are slightly smaller than the coefficients reported here.

${ }^{25}$ Enrollment rose from $5.9 \%$ of the US population in 2001 to $8.8 \%$ in 2007 . Other authors
} 
Finally, the rise in SNAP receipt may have been, in part, a bounceback from welfare reform, a channel overlooked by existing research. In the bottom panel of Figure 4, we show that states which had bigger declines in cash assistance receipt in the 1990's also had bigger increases in SNAP receipt among families with children in subsequent years $\left(t_{\text {peak }}+6\right.$ to $\left.t_{\text {peak }}+11\right)$, with an estimated coefficient of -0.45 . This coefficient likely also reflects, in part, changes in the state-level economy. We find that a $10 \log$ point decrease in caseloads during welfare reform is associated with a 0.36 percentage point increase in unemployment over the bounceback period (statistically significant). ${ }^{26}$ Therefore, we think that one reason the coefficient for the relationship between changes in cash assistance caseloads and immediate changes in SNAP is smaller than the bounceback coefficient is because the bounceback coefficient in part reflects state-level changes in unemployment.

Overall, the data show an increase in SNAP take-up during this period, with relatively stable eligibility and a stable poverty rate. It appears that both specific policy changes to improve access and bounceback from welfare reform played large roles in rising enrollment.

\section{Great Recession, 2007-2011}

The Great Recession coincided with a dramatic increase in SNAP receipt - from 26.6 million recipients in July 2007 to 45.3 million recipients in July $2011 .{ }^{27}$ Since then, enrollment has stabilized and was 47.5 million people in

have also run up against measurement error challenges in using state-level policy variables to explain caseload trends during periods of major policy change. For example, Danielson and Klerman (2008) find that measured policy variation can explain only about one-fifth of the measured decline in cash assistance receipt from 1992 to 2005.

${ }^{26}$ In addtion, SNAP enrollment for adults and seniors in these states bounced back as well.

${ }^{27}$ These estimates are the national monthly totals published by USDA. In Table 4, we report the average monthly caseload for Q3 in the QC files, which is 26.04 million recipients in 2007 and 45.14 million in 2011. Appendix D of Leftin et al. (2012) explains that the QC counts are slightly lower because they omit families receiving Disaster SNAP and cases 
April 2013, the month with the most recently available data. Hanson and Oliveira (2012) used national time series data to examine the correlation between the unemployment rate and SNAP receipt, and concluded that the increase in SNAP participation during the recent recession was "consistent with the increase during previous periods of economic decline." ${ }^{28}$ In contrast, Mulligan (2012) focuses on policy changes, noting "Millions of households received safety net benefits in 2010 that would not have been eligible for benefits in 2007 even if their circumstances had been the same in the two years, because the rules for receiving safety net benefits had changed." 29

We perform three sets of analysis to explore the sources of the increase in SNAP take-up during this period. First, we estimate the relationship between unemployment and SNAP receipt at the family level. Next we examine the connection between unemployment and SNAP receipt at the county level. Finally we examine in detail the eligibility expansions which may have increased SNAP enrollment.

\subsection{Unemployment and SNAP (Family Level)}

We begin by analyzing the family-level relationship between unemployment and SNAP receipt using data from the SIPP. ${ }^{30}$ We estimate the fraction of time that a family's labor force participants were unemployed over the past sixteen months, using data from mid-2007 and mid-2011. The top panel of Figure 6 shows that the frequency of prolonged unemployment spells rose substantially. Next, we compute the probability of SNAP receipt for families by time spent unemployed. The bottom panel of Figure 6 shows that the probability of SNAP receipt in 2007 is rising sharply by unemployment status, from $5 \%$ of people in families with no unemployment to about $60 \%$ of people in families with

which were found to be ineligible for SNAP.

${ }^{28}$ Relatedly, Anderson et al. (2012) show that the share of working-age SNAP recipients also receiving unemployment insurance rose during the recession.

${ }^{29}$ See also page 283 where he calculates that the BBCE and other eligibility changes are responsible for " 66 percent of the growth of SNAP household participation in excess of family (125 percent) poverty growth between fiscal years 2007 and 2010."

${ }^{30}$ See Appendix A.1 for details on sample construction. This sample includes all families, regardless of whether children are present. 
unemployment for sixteen consecutive months. The same strong correlation between duration and SNAP receipt exists in 2011, although the probability of SNAP receipt is higher in this later year for families with short durations. Using 2007 SNAP receipt rates by duration and the 2011 SIPP distribution of unemployment durations, we calculate a counterfactual SNAP enrollment rate in 2011 of $12.0 \%$. National SNAP receipt rose from $8.9 \%$ to $14.5 \%$ during the analysis period, so using family-level variation in unemployment rates alone, we can explain about half the increase in SNAP receipt among the entire US population (not conditional on unemployment).

When a recession hits an entire region, it becomes more difficult to turn to neighbors, family, and friends for financial support. An extensive literature in economics (e.g. Townsend (1994)) documents that people rely on local networks to smooth idiosyncratic shocks, suggesting that the impacts of unemployment on SNAP enrollment for a region will be larger than the impacts on a family alone. In addition, during the recession, economic distress could occur without measured unemployment, if a worker remained employed but had his or her hours or wage-level reduced. Indeed, we calculate using the SIPP that 31 percent of the aggregate increase in SNAP receipt from 2007 to 2011 occurs in families in which no member experienced an unemployment spell and at least one member was in the labor force. These considerations suggest benefits to analyzing the relationship between economic conditions and SNAP receipt at the local level.

\subsection{Unemployment and SNAP (Area Level)}

We estimate the relationship between local unemployment and SNAP receipt using data from 1990 through 2007, prior to the Great Recession. ${ }^{31}$ While unemployment rates were lower during this period, three states (California, West Virginia, and Michigan) had unemployment rates which exceeded $9 \%$

\footnotetext{
${ }^{31}$ An extensive literature analyzes the effect of SNAP policies and labor market conditions on enrollment at the state level. Examples include Currie and Grogger (2001); Klerman and Danielson (2011); Mabli et al. (2009); Mabli and Ferrerosa (2010); Ratcliffe et al. (2008); Ziliak et al. (2003).
} 
in the early 1990's recession. As an initial graphical example, we model the state-level relationship between unemployment and SNAP enrollment as

$$
\log S N A P_{j t}=\alpha+\beta_{0} U_{j t}+\eta_{j}+\varphi_{t}+\varepsilon_{j t}
$$

where $U_{j t}$ is the unemployment rate in state $j$ in year $t, \eta_{j}$ is a state fixed effect and $\varphi_{t}$ is a year fixed effect. We plot the results from this regression in the top panel of Figure 7 - a one percentage point increase in the state unemployment rate raises SNAP enrollment by six percent. ${ }^{32}$

Next, we build an extended version of this model using county-level data. ${ }^{33}$ We use a specification with both county- and state-level unemployment, because county-level unemployment is measured with substantial error, and state-level unemployment may not reflect important aspects of the local labor market situation. Our empirical model uses unemployment and two annual lags at the state and county-level: ${ }^{34}$

$\log S N A P_{i j t}=\alpha+\left(\begin{array}{lll}\beta_{0} & \beta_{1} & \beta_{2}\end{array}\right)\left(\begin{array}{c}U_{j t} \\ U_{j t-1} \\ U_{j t-2}\end{array}\right)+\left(\begin{array}{lll}\gamma_{0} & \gamma_{1} & \gamma_{2}\end{array}\right)\left(\begin{array}{c}U_{i j t} \\ U_{i j t-1} \\ U_{i j t-2}\end{array}\right)+\eta_{i}+\varphi_{t}+\varepsilon_{i j t}$

The results are reported in Table 3. In our first specification, we weight each county equally, and we find that the effect of the contemporaneous state-level unemployment rate, $\hat{\beta}_{0}$, is large and significant (column 1$) . \hat{\gamma}_{0}$ and $\hat{\gamma}_{1}$ are also positive and significant. The sum of all $\hat{\beta}$ and $\hat{\gamma}$ estimates is 0.11 , meaning that in a state in which every county saw a persistent one percentage point

\footnotetext{
${ }^{32}$ Mabli and Ferrerosa (2010) similarly estimate that a 1 p.p. increase in unemployment raises SNAP enrollment by $6 \%$.

${ }^{33}$ Details on construction of this sample are in Appendix A.2. This dataset has two key limitations. First, not all states report county-level enrollment statistics to FNS. In 1990, we have county-level data for $85 \%$ of SNAP enrollment, and by 2007, after some states have stopped reporting, we have county-level data for $80 \%$ of SNAP enrollment. Second, among the matched observations, there is measurement error in the county-level unemployment rate, as well as measurement error because enrollment at a county's SNAP office may not correspond to enrollment by county residents.

${ }^{34}$ We found that a third lag was statistically insignificant.
} 
increase in the unemployment rate, the model predicts an increase in SNAP enrollment reaching $11 \%$ after three years. When we weight each county by its population, the effect of unemployment is even larger (column 2), producing a $20 \%$ cumulative increase in enrollment. ${ }^{35}$

One striking feature of these estimates is that unemployment has highly persistent impacts on SNAP enrollment. ${ }^{36}$ In the bottom panel of Figure 7, we compute the impact of a 1 percentage point increase in unemployment for three years on SNAP enrollment over a five-year horizon. Some commentators (Furchtgott-Roth (2012)) have raised concerns that SNAP receipt remained high even after the unemployment rate peaked in June 2009. In fact, our estimates show that a feature of the aftermath of past recessions is persistentlyelevated SNAP receipt.

We show robustness checks to our specification in Appendix Table 3. First, we report estimates from a specification without year fixed effects $\varphi_{t}$ (columns 1 and 2). Unsurprisingly, when the national unemployment rate is higher, SNAP enrollment rises as well, and so this specification yields larger coefficients. This may reflect spillovers in the impacts of unemployment across geographies or changes in the national policy climate with respect to SNAP enrollment. Second, we use the share of the population receiving SNAP as the dependent variable (columns 3 and 4 ) and find similar magnitudes to the results in Table 3.

Measurement error seems to be a serious issue with the county unemployment data. Suppose that the true relationship between $u$ and $\log S N A P$ is $E^{*}(\log S N A P \mid u)=\beta u$, where $u$ is the true county-level unemployment

\footnotetext{
${ }^{35}$ We emphasize that these specifications do not identify the causal impact of unemployment on SNAP receipt. An increase in the unemployment rate may change local SNAP policies - an increase in client to caseworker ratios may lengthen processing time, making it harder to enroll, or governments may enact policies making it easier to enroll. Rather, these specifications characterize the historical relationship between unemployment and SNAP enrollment, to help us examine whether the path of SNAP enrollment in the Great Recession is in line with historical patterns.

${ }^{36}$ Ziliak et al. (2003) also find a persistent impact of unemployment on SNAP enrollment.
} 
rate. If in the data we observe $\hat{u}_{\text {county }}=u+\tilde{\varepsilon}$ where $u$ and $\tilde{\varepsilon}$ are both normally distributed, and we estimate $E^{*}(\log S N A P \mid \hat{u})=\hat{\beta} \hat{u}$, we will find that $\hat{\beta}=\beta \frac{\operatorname{Var}(u)}{\operatorname{Var}(u)+\operatorname{Var}(\tilde{\varepsilon})}$. This means that $\hat{\beta}$ will be biased toward zero. Intuitively, when the unemployment rate is difficult to measure, it will be harder to detect statistically a relationship between unemployment and SNAP receipt. To the extent that measurement error is an issue, regardless of the error distribution, lowering $\operatorname{Var}(\tilde{\varepsilon})$ will raise $\hat{\beta}$. Two pieces of evidence suggest a role for measurement error. First, measurement error is likely to be larger for counties with small populations and weighting each county by its population leads to larger point estimates. Second, if we knew the true county-level unemployment rate $u$, and there were no spillover effects from nearby counties, then the coefficients on state-level unemployment should be zero. In fact, we find that they tend to be even larger than the county coefficients. ${ }^{37}$

We use the pre-recession model to predict the consequences of unemployment changes for SNAP enrollment in the Great Recession. We predict the annual change in enrollment in each county using the equation

$$
\Delta \log \operatorname{snap}_{i j t}=\sum_{k=0}^{2} \hat{\beta}_{k} \Delta u_{j, t-k}+\hat{\gamma}_{k} \Delta u_{i j, t-k}
$$

where $\Delta u_{j, t-k}$ is the change from the previous year in state unemployment and $\Delta u_{i j, t-k}$ is the county-level change. ${ }^{38}$ To predict the change in national

\footnotetext{
${ }^{37}$ Because these coefficients are both biased towards zero due to measurement error, they likely imply that SNAP receipt has risen less in the Great Recession than we might expect due to changes in the unemployment rate. If the county-level unemployment data were simply smaller samples of the state data, we could assess the extent of bias from measurement error and adjust for it. The actual data generating process for the county unemployment rates is more complicated, and involves allocating the state-wide unemployment across counties based upon county-level administrative data counts of unemployment beneficiaries. A fuller analysis of measurement error - both in mismatch between unemployment and SNAP geographies and also in the construction of county-level unemployment rates - is beyond the scope of this paper, but would be valuable for future work.

${ }^{38}$ While measurement error in local unemployment is a source of bias for estimating $\hat{\beta}$ and $\hat{\gamma}$, it will not bias our prediction for the path of unemployment in the recession given a set of coefficients $\hat{\beta}$ and $\hat{\gamma}$. Formally, $\Delta \widehat{\log s n} a p_{i j t}=E\left(\sum_{k=0}^{2} \hat{\beta}_{k}\left(\Delta u_{j, t-k}+\varepsilon_{j, t-k}\right)+\hat{\gamma}_{k}\left(\Delta u_{i j, t-k}+\right.\right.$ $\left.\left.\eta_{j, t-k}\right)\right)=E\left(\sum_{k=0}^{2} \hat{\beta}_{k}\left(\Delta u_{j, t-k}\right)+\hat{\gamma}_{k}\left(\Delta u_{i j, t-k}\right)\right)$ by the linearity of our prediction equation.
} 
SNAP enrollment relative to 2007, we sum over all the counties, taking a population-weighted average:

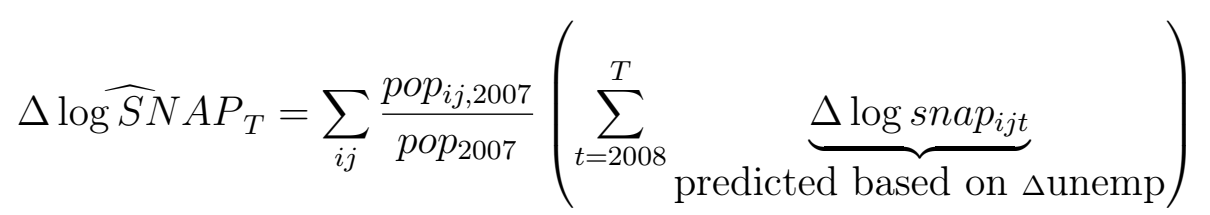

We compute this prediction for all counties, regardless of whether data was available on SNAP enrollment there. ${ }^{39}$

Using the coefficients from the specification which weighted counties by population, we predict that SNAP enrollment would have risen by 18.7 million people by July 2011 (98\% of the observed increase). Using the equal-weighted specification, we predict an increase of 13.5 million ( $71 \%$ of the observed increase) ${ }^{40}$

These estimates should be treated with caution. A sharp, sustained increase in unemployment rates may have different effects on SNAP enrollment than a smaller, more-transitory increase. With this caveat, the model's predicted timing and magnitude of the SNAP enrollment response are quite similar to the observed data. These estimates are consistent with interpreting the increase in SNAP enrollment as an automatic stabilizer responding to a very bad labor market situation in a way that is similar to how SNAP has performed in past downturns.

\subsection{Eligibility Expansions}

Next, we examine the role of policies which expanded SNAP eligibility in the recession. We focus in particular on two policies: increased state-level

\footnotetext{
${ }^{39}$ We also computed a prediction for the change in national enrollment weighting each county by its SNAP enrollment $\left(\sum_{i j}\right.$ snap $\left._{i j, 2007}\left(\log s n a p_{i j t}-\log s n a p_{i j, 2007}\right)\right)$ and obtained very similar results.

${ }^{40}$ For July 2012, the population-weighted model predicts $92 \%$ of the observed increase, and the equal-weighted model predicts $54 \%$ of the observed increase. The prediction from the equal-weighted model shrinks more, because that model puts more weight on the second lag of unemployment and less weight on the third lag, and unemployment is falling during 2012.
} 
adoption of Broad-Based Categorical Eligibility (BBCE) and waivers on time limits for Able-Bodied Adults Without Dependents (ABAWDs) that states become eligible for when unemployment rates are high. These results for enrollment are summarized in Table 4. We repeat the exercise for benefits, and the results are shown in Appendix Table 4.

BBCE, a policy option introduced in 2001 which allows states to relax income and asset limits on eligibility, is described in detail in Section 4. In 2007, according to the SNAP Policy Database, 13 states had adopted some version of BBCE. USDA administrators issued a memo in September 2009 (Shahin (2009)) encouraging states to start using BBCE, and by 2011, 41 states had adopted BBCE. Using the QC files, we estimate that in 2011, 1.7 million people (3.9\% of total enrollment) lived in households whose income was too high to be SNAP-eligible under normal program rules and therefore were enrolled only because of BBCE. ${ }^{41}$ We construct a counterfactual by assuming that enrollment for people with excess income would have grown at the same rate between 2007 and 2011 as enrollment of people eligible under standard rules. Under this assumption, new adoption of BBCE raised enrollment of people with excess income by 1.0 million. In other words, we estimate that of the 1.7 million indivdiuals eligible because of BBCE in 2011, 700,000 were eligible based on pre-2007 state adoption of BBCE and 1,000,000 were eligible because of recession-era adoption. ${ }^{42}$

BBCE also allowed states to raise or eliminate asset limits. Because caseworkers do not record assets in BBCE states, we cannot count enrollment with excess assets using the QC files. In 2011, Idaho and Michigan reinstated asset limits of $\$ 5,000$ and caseloads fell by 1 percent or less (Government Account-

\footnotetext{
${ }^{41}$ Precisely, we classify a household as exceeding standard income limits due to BBCE if (1) they are not receiving pure cash assistance (because they are already categorically eligible) and (2) they have net income $>100 \%$ of poverty. We also flag households with gross income $>130 \%$ of poverty if they do not have a senior or a disabled person. Our estimates are very similar to those reported by Government Accountability Office (2012) (Table 2) and Trippe and Gillooly (2010) (Table C4.2).

${ }^{42}$ Using the same methodology, we calculate that recession-era BBCE adoption raised benefit expenditures on people with excess income by $\$ 200$ million in 2011 .
} 
ability Office (2012)). Based on this evidence, we estimate that adoption of $\mathrm{BBCE}$ during the recession raised enrollment of people with excess assets by $560,000 .^{43}$

Welfare reform (PRWORA) subjected ABAWDs who are working less than half time or not meeting employment-training requirements to a 3-month time limit on SNAP benefits during any 36-month period. However, the legislation established a waiver of time limits in places with elevated unemployment. ${ }^{44}$ Without time limits, more people are eligible, and there is greater incentive to apply, given the potential for a longer duration of receipt. Conceptually, because state eligiblity for ABAWD waivers mechanically expands and shrinks with the unemployment rate, these waivers have a lot in common with conventional automatic stabilizers, even though they require a state decision to apply for the waivers for them to go into effect. ${ }^{45}$

In 2007, about one-third of the SNAP enrollment was in places with a waiver. As the country headed into recession, nearly all places became eligible for waivers. ${ }^{46}$ In 2011, we estimate that 4.3 million SNAP recipients $(9.5 \%$ of

\footnotetext{
${ }^{43}$ Idaho and Michigan reinstated asset limits of $\$ 5,000$, which included some people who would have been excluded by a $\$ 2,000$ asset limit. Using the Survey of Consumer Finances, we estimate that asset limits of $\$ 2,000$ would have caused caseloads to fall twice as much as a $\$ 5,000$ limit. Based on this fact, we assume that people with excess assets account for $2 \%$ of the total caseload in BBCE states. In 2007, the 11 states without asset tests accounted for $18 \%$ of SNAP enrollment and in 2011, the 39 states without asset tests in 2011 accounted for $79 \%$ of total SNAP enrollment. We calculate the total number of individuals affected as $.02 \times(.79-18) \times 45$ million. This could be an overestimate if the true impact of the Idaho and Michigan policy changes analyzed by the GAO was less than 1 percent rather than equal to 1 percent. Because we lack micro data on these asset limit changes, in constructing an annual pattern of the impact of these changes for Figure 8 we assume that enrollment for cases with excess assets grew linearly from 2007 to 2011.

${ }^{44}$ A "place" may be a city, a county, or a group of counties. Commonly used criteria are if a place has an unemployment rate is 20 percent higher than the national average, has unemployment above 10\%, is designated by the Department of Labor as a "Labor Surplus Area", or has a "low and declining employment-population ratio."

${ }^{45}$ Some portion of the coefficients estimated using equation 8 likely reflects the business cycle pattern of ABAWD waivers because about half of our 1990 to 2007 sample period is after the new waiver procedures were set up.

${ }^{46}$ USDA administrators issued a memo on January 8, 2009 (Foley (2009)) saying that states with Extended Unemployment Compensation for unemployment insurance were al-
} 
total enrollment) were potential ABAWDs using the QC files. ${ }^{47}$ If enrollment for this group had instead grown at the same rate as enrollment of people eligible under standard rules, there would be about 2.5 million potential ABAWDs receiving SNAP. Under this assumption, the recession-induced waivers raised enrollment by 1.9 million people. ${ }^{48}$

We find that the impact of BBCE adoption and ABAWD waivers was smaller in terms of benefit dollars than in terms of enrollment. Real spending in 2011 dollars rose from $\$ 31.9$ billion in 2007 to $\$ 71.9$ billion in 2011, an increase of $\$ 40.0$ billion. BBCE adoption raised spending by $\$ 1.1$ billion, accounting for $3 \%$ of the increase, and ABAWD waivers raised spending by $\$ 3.6$ billion, accounting for $9 \%$ of the increase. Put another way, total SNAP spending increased by $6 \%$ as a result of these policy changes.

Finally, the Recovery Act temporarily raised the maximum SNAP benefit by $13.6 \%$, which increased the incentive to enroll and may have raised takeup among the already eligible. It is difficult to quantify the impact of this change because SNAP benefits are set at the federal level. However, a series of papers estimating the take-up elasticity for unemployment insurance, another program which serves people with temporary economic need, finds values between 0.19 and $0.59 .^{49}$ Applying this range to the $18 \%$ increase in average

lowed to waive ABAWD time limits. Nearly all states had EUC during the recession, which qualified them for an ABAWD waiver. Then, the Recovery Act issued a national waiver of time limits through FY2010. After this authority expired, nearly all states received waivers in FY2011 due to continued labor market weakness.

${ }^{47}$ We classify a person as a potential ABAWD if they are: ages $18-49$, have no children in the household, are working less than 30 hours a week, and are not disabled. Following Leftin et al. (2012), we define a person disabled if (1) they have SSI income, (2) the household has no elderly members and a medical deduction, or (3) the person is exempt from work registration due to disability, and has income from Social Security, veterans' benefits, or workers' comp. We classify these people as "potential" ABAWDs because many had enrolled within the previous three months, and likely had not exhausted their time limits. For example, $29 \%$ of potential ABAWDs in FY2011 had enrolled within the last three months.

${ }^{48}$ Using the same methodology, we calculate that recession-induced waivers raised benefit expenditures by $\$ 3.6$ billion in 2011 .

${ }^{49} \mathrm{McCall}$ (1995) uses the CPS Displaced Worker Survey to estimate a that a $10 \%$ increase in UI benefits raises benefit expenditure through takeup by 1.9\%-3.0\%. Anderson and Meyer (1997) use administrative data from six state UI programs to estimate an elasticity between 
household SNAP benefits implies an increase in enrollment of $3 \%$ to $11 \%$.

\subsection{Summary and Reconciliation with Literature}

Figure 8 summarizes our enrollment results for unemployment and eligibility expansions together. We find that expanded adoption of BBCE raised enrollment by 1.57 million people, and automatic waivers of time limits raised enrollment by 1.87 million people, for a total of 3.44 million. Together, these two changes can account for $18 \%$ of the total increase in enrollment over this period. Beyond that, unemployment raises SNAP receipt both by increasing the number of people who are eligible and increasing need among eligibles. ${ }^{50}$ Recall that we estimated two different specifications for the impact of unemployment on SNAP enrollment - one which weighted each county equally and another which weighted counties according to population. The equal-weighted estimate is shown in the top panel, and here our model slightly underpredicts the actual increase in SNAP enrollment. The population-weighted estimate, in the bottom panel, slightly overpredicts the actual values in 2010 and 2011. A simple decomposition suggests that for the other 15.7 million people who enrolled in SNAP about one-third is attributable to increases in the number of eligible individuals, holding program rules fixed, and two-thirds is attributable to increases in the take-up rate. ${ }^{51}$

SNAP enrollment rose by 19.1 million people from July 2007 to July 2011, an unprecedented increase, but one that the estimates from our unemployment regressions indicate was mostly the result of the program's built-in automatic stabilizer features operating as usual in the midst of a very severe recession.

Mulligan (2012) estimates that post-2007 policy changes increased SNAP

0.39 and 0.59 .

${ }^{50}$ We believe that our model is conservative in only focusing on the unemployment rate. In particular, other household economic measures suggest that the Great Recession was a time of very serious economic need. Long-term unemployment and food insecurity reached all-time highs.

${ }^{51}$ The number of people living below $125 \%$ of the poverty line increased by a factor of 1.2 , while the number of people enrolled in SNAP, after subtracting 3.3 million for reasons detailed above, increased by a factor of 1.58 . 
enrollment by 20.3 percent. Our comparable number is that these changes account for 7.5 percent of enrollment in 2011.

Mulligan (pages 79-81) assumes that adoption of relaxed vehicle policies during the recession and changes in asset policies in the 2008 Farm Bill raised participation by $12 \%{ }^{52}$ However, the SNAP Policy Database shows that by 2007, 46 states had already adopted relaxed vehicle policies (see Table 2). The 2008 Farm Bill excluded retirement accounts and 529s from the asset test; this had a minimal impact on eligibility, given that asset limits bind so rarely, as discussed above.

Mulligan further assumes that BBCE raised enrollment nationally by an additional $6 \%$, which is larger than our estimate of $3.5 \%$. His estimate comes from comparing the differential increase in SNAP enrollment among states that had adopted BBCE by 2010 relative to the ones that had not. However, if state economic conditions affect the decision to adopt $\mathrm{BBCE}$, then this estimate will conflate the impact of those conditions with the impact of the eligiblity expansion. States with BBCE by 2010 had unemployment rates averaging $9.2 \%$, while the unemployment rate in non-BBCE states averaged $7.6 \%$. Thus, it seems quite possible that part of the differential SNAP enrollment by BBCE states was a reflection of their greater economic distress. In contrast, our estimates directly count the number of individuals who were eligible under the eligiblity expansions but would not have been eligible in their absence.

Finally, in assessing the impact of waiving ABAWD time limits, Mulligan does a QC-based calculation that is quite similar to ours. He concludes that the waiver of time limits raised enrollment by $2.3 \%$, which is smaller than

\footnotetext{
${ }^{52}$ Mulligan cites Ratcliffe et al. (2007) as finding that exempting a vehicle from the asset test raises participation by $8-16 \%$, and takes the midpoint of $12 \%$ as his estimate (see Ratcliffe et al. (2008) for the published version). Ratcliffe et al. (2007) uses SIPP data in its analysis. Another paper using the SIPP, Hanratty (2006), reports that exempting one vehicle changed enrollment by negative $5.5 \%$ to positive $7 \%$. Estimates for the impact of vehicle exemptions using state-level administrative enrollment counts are: $0.8 \%-1.2 \%$ from Mabli et al. (2009) and 0.4\%-0.9\% from Klerman and Danielson (2011). In Appendix Table 2 , we estimate with state-level data that exempting at least one vehicle raises enrollment by $2 \%$.
} 
our estimate of 4.1\%. In Table 5, we provide a side-by-side comparison of our estimates and Mulligan's which summarizes the discussion in this section.

\section{Conclusion}

In this paper, we examine changes in SNAP enrollment over the past twenty years. We show that a strong economy and welfare reform contributed to falling enrollment in the 1990's, and policy efforts to make the program more accessible to workers and a bounceback from welfare reform caused enrollment to rise between 2001 and 2007. Research on SNAP enrollment in the Great Recession has been limited, and we attempt to fill this gap. We find that SNAP acts as a automatic stabilizer: unemployment and temporary business-cycle sensitive rule changes for adults without children were much more important than state-level policy expansions in producing the surge in enrollment from 2007 to 2011. 


\section{References}

Acs, G. and Schwabish, J. A. (2011). Assessing the Changing Relationship Between Food Stamps and Work.

Almond, D., Hoynes, H. W., and Schanzenbach, D. W. (2011). Inside the War on Poverty: The Impact of Food Stamps on Birth Outcomes. Review of Economics and Statistics, XCIII(2):387403.

Anderson, P. and Meyer, B. D. (1997). Unemployment Insurance Take-up Rates and the After-Tax Value of Benefits. Quarterly Journal of Economics, 112(3):913-937.

Anderson, T., Kirlin, J. A., and Wiseman, M. (2012). Pulling Together: Linking Unemployment Insurance and Supplemental Nutrition Assistance Program Administrative Data to Study Effects of the Great Recession. Technical report, Publications from USDA-ARS / UNL Faculty. Paper 943.

Auerbach, A. J. (2003). Is There a Role for Discretionary Fiscal Policy? In Rethinking Stabilization Policy, pages 109-150. Federal Reserve Bank of Kansas City.

Bitler, M. and Hoynes, H. (2013). The More Things Change, the More They Stay the Same: The Safety Net, Living Arrangements, and Poverty in the Great Recession.

Blanchard, O., DellAriccia, G., and Mauro, P. (2010). Rethinking Macroeconomic Policy. Technical report, International Monetary Fund Staff Position Note.

Blinder, A. (2006). The Case Against the Case Against Discretionary Fiscal Policy. In Kopcke, R. W., Tootell, G. M., and Triest, R. K., editors, The Macroeconomics of Fiscal Policy, pages 25-61. MIT Press.

Blundell, R. and Pistaferri, L. (2003). Income volatility and household consumption: The impact of food assistance programs. Journal of Human Resources, 38.

Borjas, G. J. (2004). Food Insecurity and Public Assistance. Journal of Public Economics, 88:14211443.

Bost, E. (2001). June 27, 2001 Testimony before the House Committee on Agriculture.

Castner, L. and Henke, J. (2011). Benefit Redemption Patterns in the Supplemental Nutrition Assistance Program. Technical report, Mathematica Policy Research.

Cunnyngham, K. (2002). Trends in Food Stamp Program Participation Rates: 1994-2000. Technical report, Mathematica Policy Research.

Cunnyngham, K. and Smith, J. (2013). Technical Working Paper: Development of the 2010 CPSBased Eligibility Estimates, SNAP QC-Based Participation Estimates, and SNAP Participation Rates. Technical report, Mathematica Policy Research.

Cunnyngham, K., Sukasih, A., and Castner, L. (2013). Empirical Bayes Shrinkage Estimates of State Supplemental Nutrition Assistance Program Participation Rates in 2008-2010 for All Eligible People and the Working Poor. Technical report, Mathematica Policy Research.

Currie, J. and Grogger, J. (2001). Explaining Recent Declines in Food Stamp Program Participation. Brookings-Wharton Papers on Urban Affairs, pages 203-244. 
Danielson, C. and Klerman, J. A. (2008). Did Welfare Reform Cause the Caseload Decline? Social Service Review, 82(4):703-730.

Dickert-Conlin, S., Fitzpatrick, K., and Tiehen, L. (2011). The Role of Advertising in the Growth of the SNAP Caseload.

Eslami, E., Leftin, J., and Strayer, M. (2012). Supplemental Nutrition Assistance Program Participation Rates: Fiscal Year 2010. Technical report, Mathematica Policy Research.

Foley, A. (2009). ABAWD Statewide Waivers - New Criteria for Unemployment Insurance Extended Benefits Trigger. Technical report, USDA Food and Nutrition Service.

Furchtgott-Roth, D. (2012). The Food Stamp Recovery: The Unprecedented Increase in the Supplemental Nutrition Assistance Program. Technical report, Manhattan Institute for Policy Research.

Government Accountability Office (1999). Food Stamp Program: Various Factors Have Led to Declining Participation.

Government Accountability Office (2012). Supplemental Nutrition Assistance Program: Improved Oversight of State Eligibility Expansions Needed. Technical report.

Gundersen, C. and Ziliak, J. P. (2003). The Role of Food Stamps in Consumption Stabilization. Journal of Human Resources, 38.

Hanratty, M. (2006). Has the Food Stamp Program Become More Accessible? Impacts of Recent Changes in Reporting Requirements and Asset Eligibility Limits. Journal of Policy Analysis and Management, 25(3):603-621.

Hanson, K. and Oliveira, V. (2012). How Economic Conditions Affect Participation in USDA Nutrition Assistance Programs. Technical report, Economic Information Bulletin of Economic Research Service.

Hastings, J. and Washington, E. (2010). The First of the Month Effect: Consumer Behavior and Store Responses. American Economic Journal: Economic Policy, 2(2):142-162.

Hoynes, H. and Schanzenbach, D. W. (2009). Consumption Responses to In-Kind Transfers: Evidence from the Introduction of the Food Stamp Program. American Economic Journal: Applied Economics, 1(41):109-139.

Kabbani, N. and Wilde, P. E. (2003). Short Recertification Periods in the U.S. Food Stamp Program. Journal of Human Resources, 38.

Klerman, J. and Danielson, C. (2011). Transformation of the Supplemental Nutrition Assistance Program. Journal of Policy Analysis and Management, 30(4):863-888.

Leftin, J., Eslami, E., Bencio, K., Filion, K., and Ewell, D. (2012). Technical Documentation for the Fiscal Year 2011 Supplemental Nutrition Assistance Program Quality Control Database and the QC Minimodel. Technical report, Mathematica Policy Research.

Leftin, J. and Wolkwitz, K. (2009). Trends in Supplemental Nutrition Assistance Program Participation Rates: 2000 to 2007. Technical report, Mathematica Policy Research.

Mabli, J. and Ferrerosa, C. (2010). Supplemental Nutrition Assistance Program Caseload Trends and Changes in Measures of Unemployment, Labor Underutilization, and Program Policy from 2000 to 2008. Technical report, Mathematica Policy Research. 
Mabli, J., Sama Martin, E., and Castner, L. (2009). Effects of Economic Conditions and Program Policy on State Food Stamp Program Caseloads, 2000 to 2006. Technical Report 56, Mathematica Policy Research.

McCall, B. (1995). The Impact of Unemployment Insurance Benefit Levels on Recipiency. Journal of Business and Economic Statistics, 13(2):189-198.

McKay, A. and Reis, R. (2013). The role of automatic stabilizers in the U.S. business cycle.

Meyer, B., Mok, W. K., and Sullivan, J. X. (2009). The Underreporting of Transfers in Household Surveys: Its Nature and Consequences.

Meyer, B. and Rosenbaum, D. (2001). Welfare, The Earned Income Tax Credit, and the Labor Supply of Single Mothers. Quarterly Journal of Economics, pages 1063-1114.

Meyer, B. D. and Goerge, R. (2011). Errors in Survey Reporting and Imputation and Their Effects on Estimates of Food Stamp Program Participation.

Mulligan, C. (2012). The Redistribution Recession: How Labor Market Distortions Contracted the Economy. Oxford University Press.

Ratcliffe, C., McKernan, S.-M., and Finegold, K. (2007). The Effect of State Food Stamp and TANF Policies on Food Stamp Program Participation. Technical report, Urban Institute.

Ratcliffe, C., McKernan, S.-M., and Finegold, K. (2008). Effects of Food Stamp and TANF Policies on Food Stamp Receipt. Social Service Review, 82(2):291-334.

Ribar, D. C., Edelhoch, M., and Liu, Q. (2008). Watching the Clocks: The Role of Food Stamp Recertification and TANF Time Limits in Caseload Dynamics. Journal of Human Resources, $43(1)$.

Schwabish, J. A. (2012). Downloading Benefits: The Impact of Online Food Stamp Applications on Participation.

Shahin, J. (2009). Improving Access to SNAP through Broad-Based Categorical Eligibility. Technical report, USDA Food and Nutrition Service.

Shapiro, J. (2005). Is There a Daily Discount Rate? Evidence from the Food Stamp Nutrition Cycle. Journal of Public Economics, 89(2-3):303-325.

Townsend, R. (1994). Risk and Insurance in Village India. Econometrica, 62(3):539-591.

Trippe, C. and Gillooly, J. (2010). Non Cash Categorical Eligibility For SNAP: State Policies and the Number and Characteristics of SNAP Households Categorically Eligible Through Those Policies. Technical report, Mathematica Policy Research.

Ziliak, J. P., Gundersen, C., and Figlio, D. N. (2003). Food Stamp Caseloads over the Business Cycle. Southern Economic Journal, 69(4):903-919. 


\section{FIGURE 1 - SNAP Take-up Rate and Enrollment}

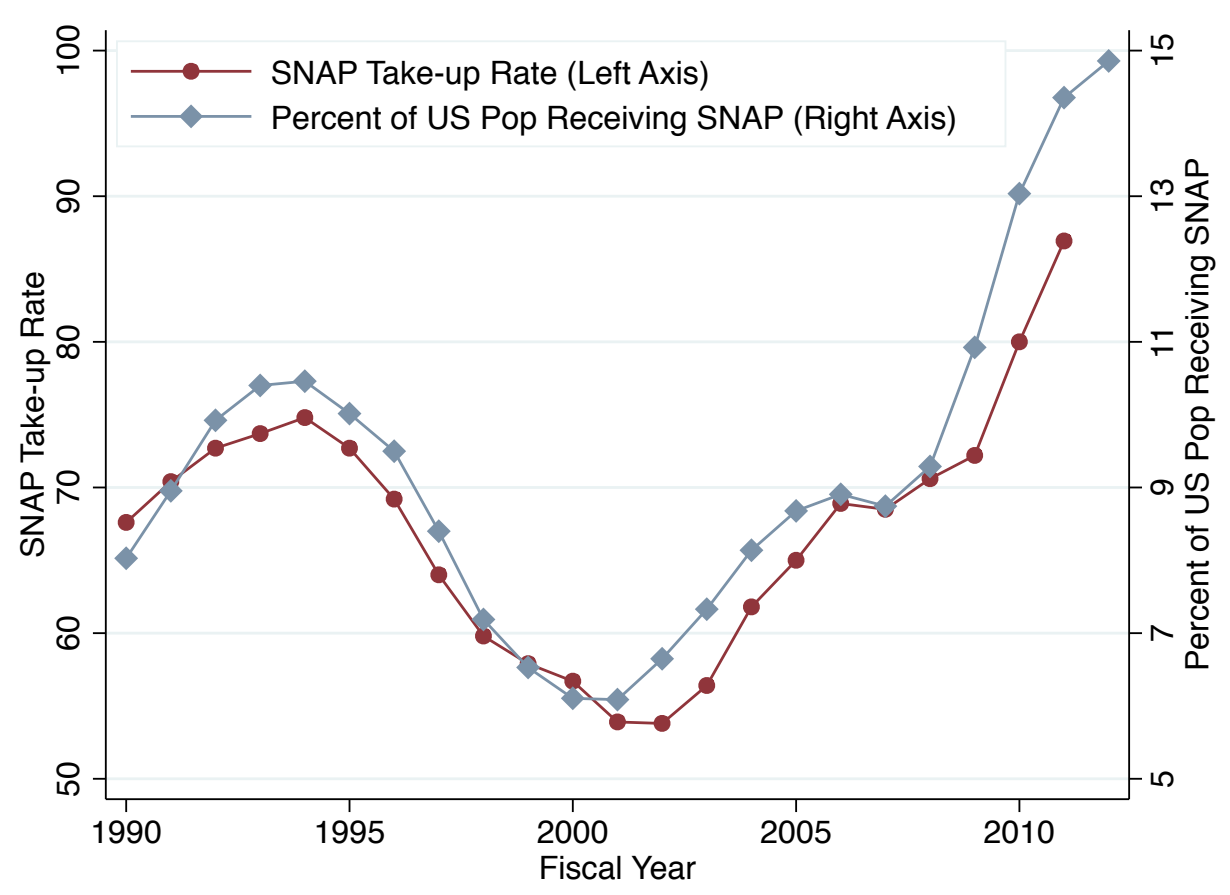

Notes: Eslami et al. (2012) of Mathematica Policy Research estimate the takeup rate as average monthly SNAP enrollment using administrative data, divided by the number of people estimated to be eligible using data on annual income from the March CPS, combined with adjustment procedures for a variety of program requirements including legal residency, asset tests, and work requirements.

Because of changes over time in its methodology for estimating the take-up rate, Mathematica does not publish a consistent time series for take-up. In order to produce a consistent series, we splice together the 1993 and 1994 estimates. Under the old methodology, the take-up rate was $61.4 \%$ in 1994 and under the new methodology, it was $74.8 \%$. For estimates prior to 1994 , we compute Take $_{t}=$ Take $_{t}^{\text {old method }}+74.8-61.4$. Mathematica changed its methodology in 2010, but provided a time-consistent estimate in Figure 1 of Eslami et al. (2012). No estimate is available yet for 2011. A crude way to estimate the 2011 take-up rate is to calculate the ratio of enrollment to the number of people with income less than $125 \%$ of poverty in calendar year $t$, which is $66.4 \%$ in 2010 and $73.3 \%$ in 2011 . We estimate Take $_{2011}=$ Take $_{2010}+(73.3-66.4)$. Finally, Mathematica changed its methodology in 1999 and 2002, but those changes affected the estimated take-up rate by no more than half a percentage point, and we make no adjustment. 


\section{FIGURE 2 - SNAP Enrollment by Household Type}
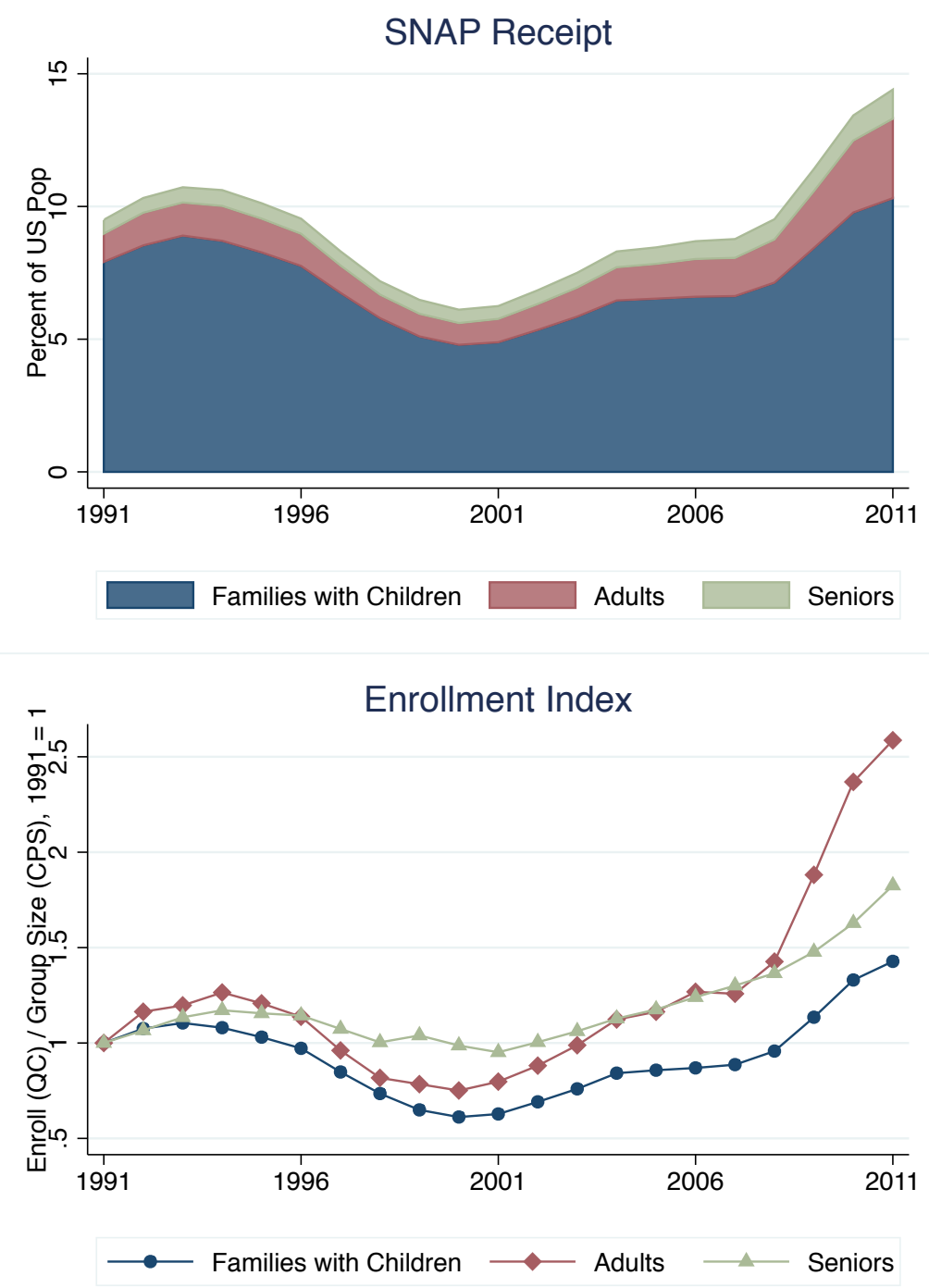

Notes: We partition households in the SNAP QC files into "Families with Children" - any unit with members under 18, "Adults" - no children, at least one nonsenior adult (ages 18-59) and "Seniors" - all members are seniors. In the top panel, we show the number of people in each group as a share of the number of people in the US. In the bottom panel, we compute changes in the number of enrollees divided by the number of families of this type in the March CPS, with the ratio scaled to a 1991 base. 


\section{FIGURE 3 - SNAP Entrances and Exits}

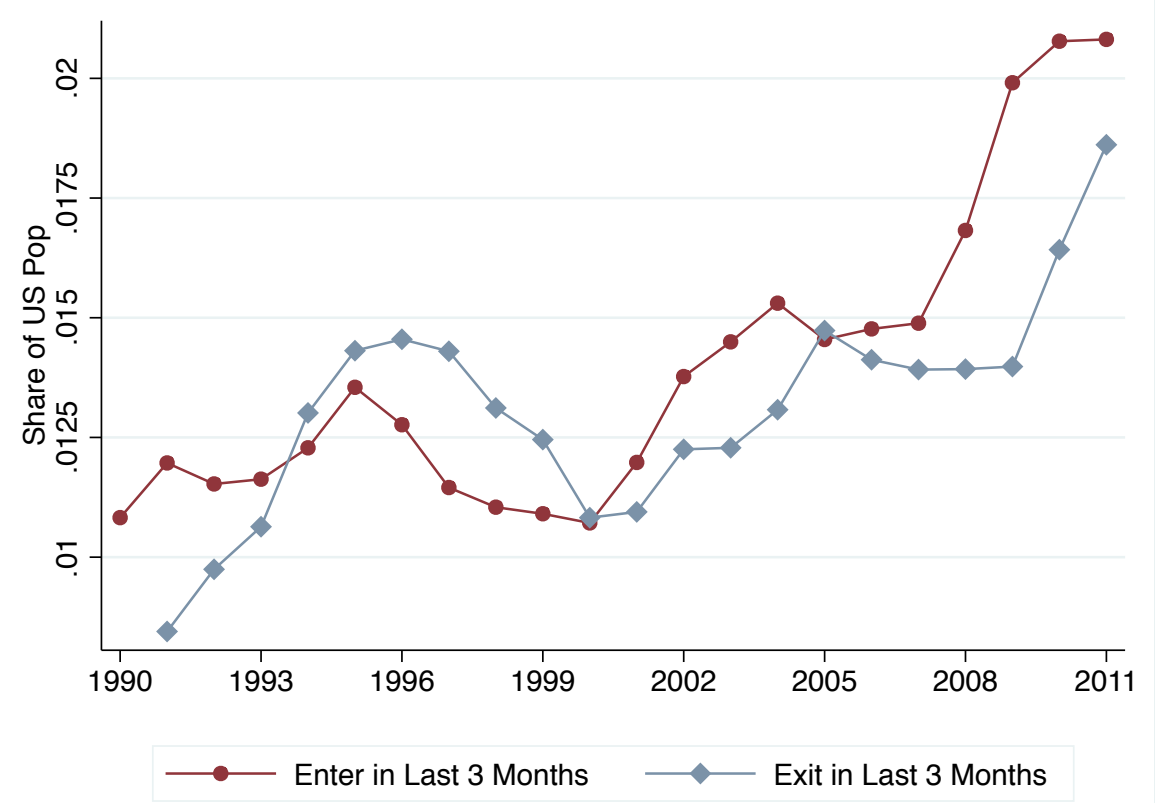

Notes: We construct an indicator for whether someone entered SNAP in last three months using the SNAP QC files. We estimate exits using the statistical identity recip $p_{t}-$ recip $_{t-1}=$ enter $_{t}-$ exit $_{t}$, where $t$ indexes quarters. See Section 2.2 for details. 


\section{FIGURE 4 - Welfare Reform and SNAP Caseloads}
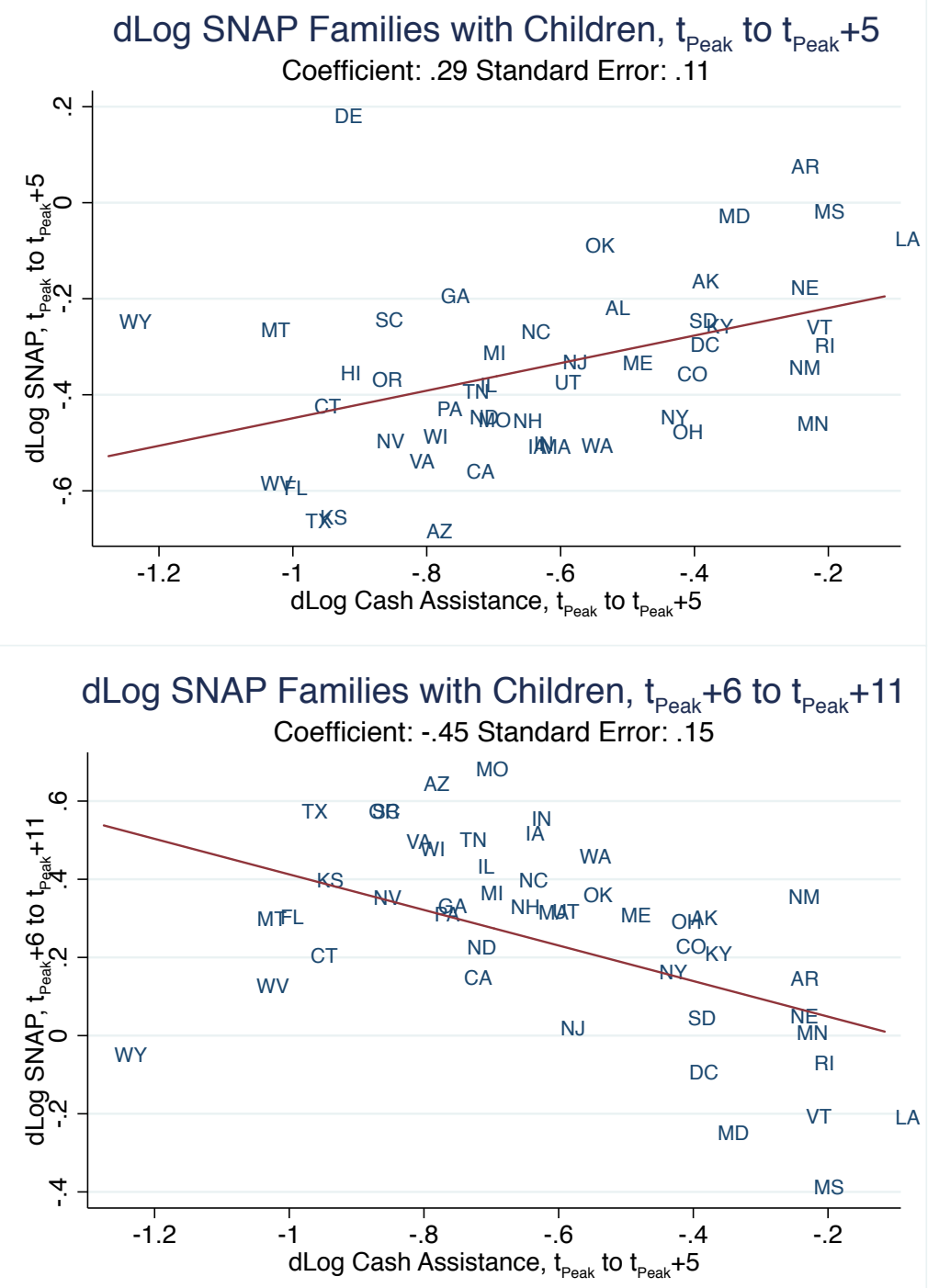

Notes: $t_{\text {peak }}$ is the year in which a state had its maximum number of cash assistance recipients. For 41 states, this peak occurred between 1992 and 1994. The $\mathrm{x}$-axis in both panels is the change in the number of welfare recipients (expressed in $\operatorname{logs}$ ) from $t_{\text {peak }}$ to $t_{\text {peak }}+5$. Idaho is an outlier and is omitted; there, welfare receipt fell by $234 \log$ points (from 24,282 recipients in 1995 to 2,397 in 2000), and SNAP receipt fell by $35 \mathrm{log}$ points. The y-axis is the change in the number of SNAP recipients (expressed in logs) in families with children, from the QC files. 


\section{FIGURE 5 - Impact of State-Level Policy Adoption on Take-up and Enrollment}
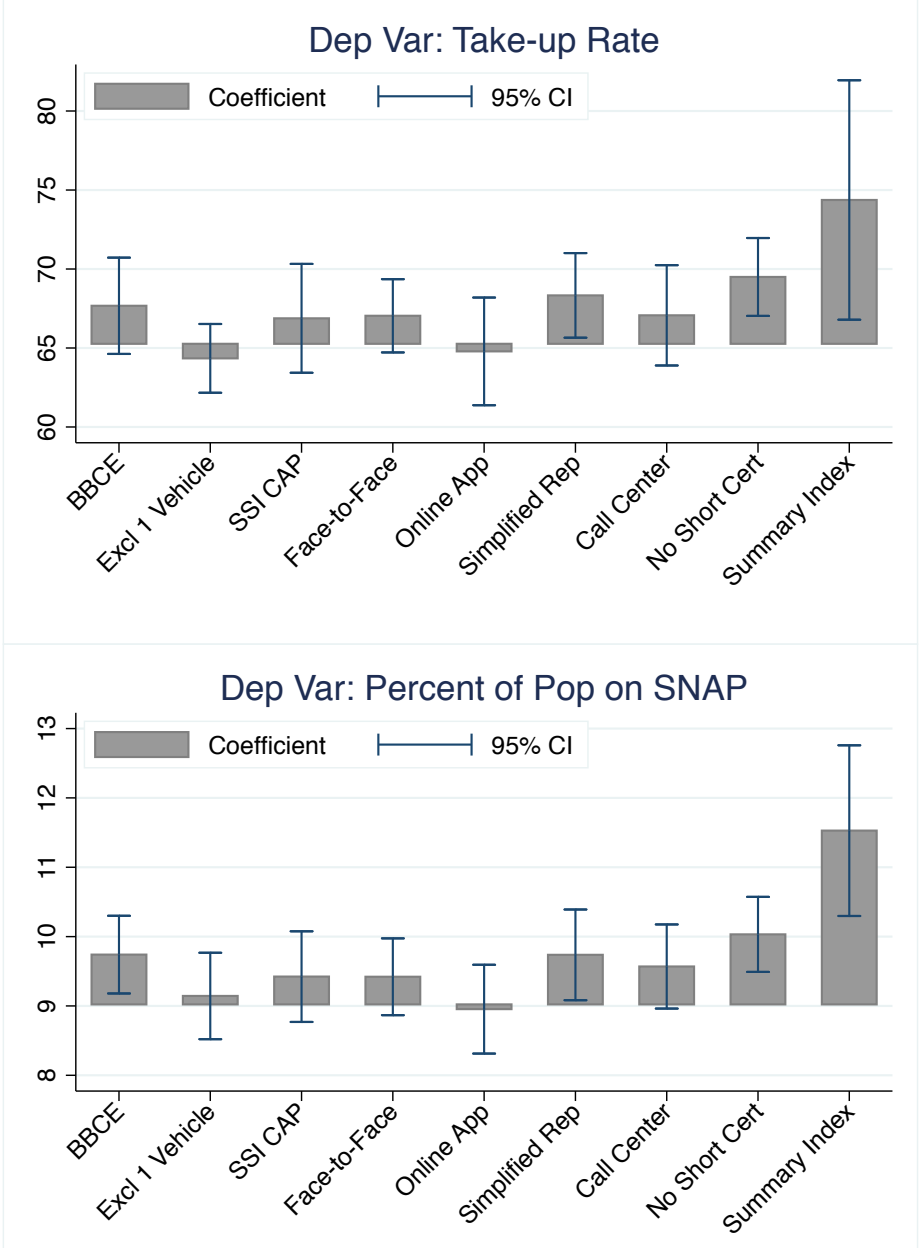

Notes: Each bar is a coefficient from a separate regression with a single policy indicator, plus state and year fixed effects. The summary index is the sum of all eight policy indicators divided by 8 . Sample is 50 states plus DC annually from 1996 through 2010. Impacts are shown relative to sample mean for take-up rate $(65.3 \%)$ and the percent of the population receiving SNAP (9.0\%). Policy data comes from each year's July record in SNAP Policy Database. Take-up rate is the average of all values reported in State Participation Reports (Cunnyngham et al. (2013) is the most recent report). SNAP enrollment is for July. States are weighted equally. Standard errors are clustered by state. Appendix Table 2 shows the coefficients and standard errors in table form. 


\section{FIGURE 6 - Family-Level Effect of Unemployment on SNAP Enrollment}
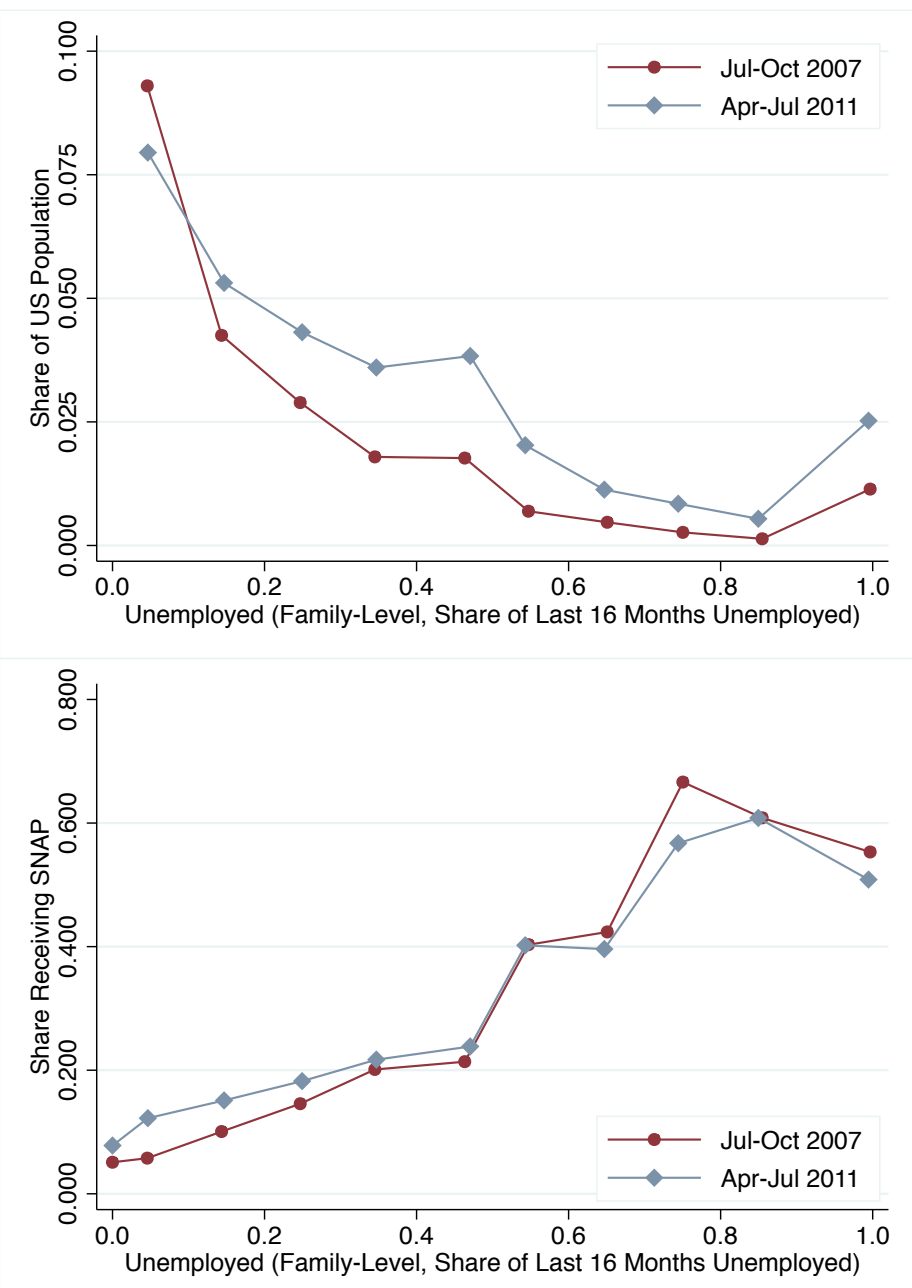

Notes: We analyze the impact of family-level unemployment on SNAP receipt using the SIPP. We estimate the fraction of time that a family's labor force participants were unemployed over the past sixteen months. In the top panel, we plot the share of the US population in families with different amounts of time spent unemployed. Always-employed families are $63 \%$ of the population in 2007 and $54 \%$ in 2011. Families with no labor force participation are 14\% in both 2007 and 2011. See Section 5.1 for discussion. 


\section{FIGURE 7 - Area-Level Effect of Unemployment on SNAP Enrollment}
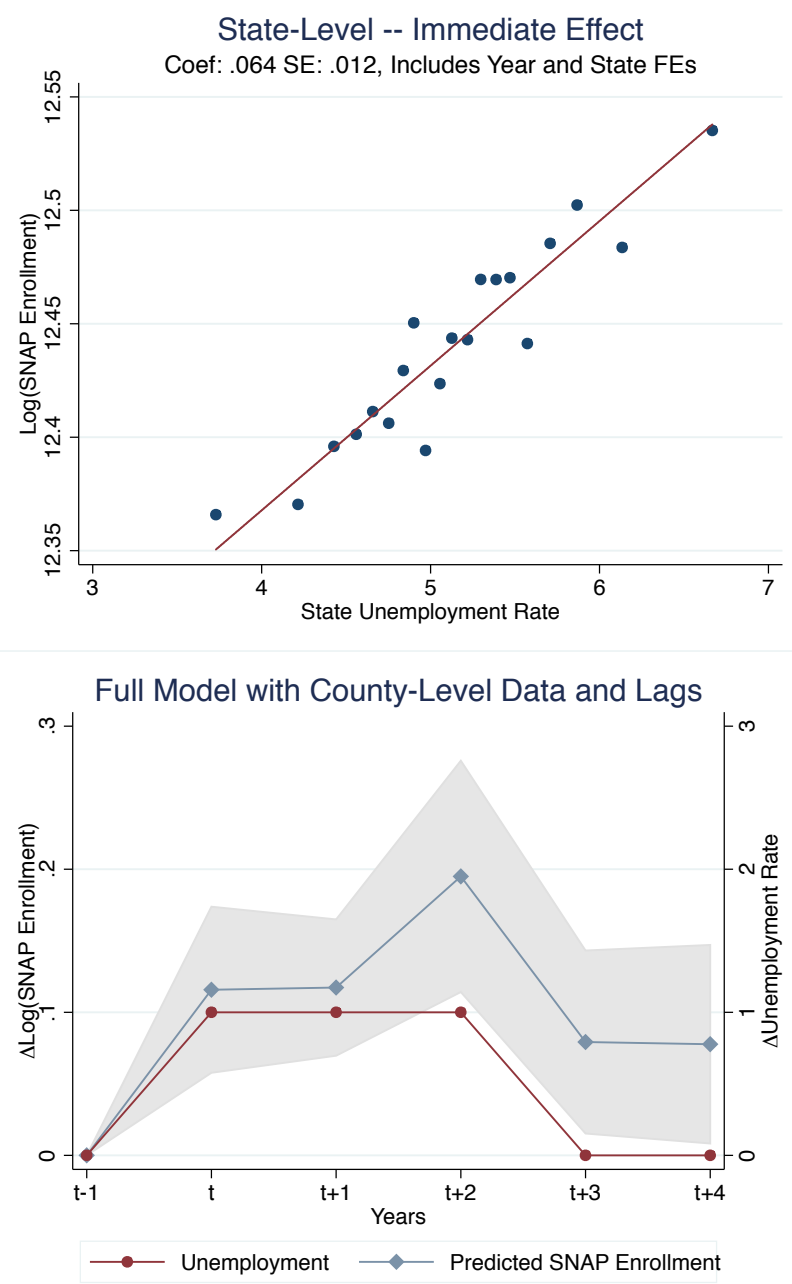

Notes: The first panel shows the relationship between state unemployment and SNAP enrollment from 1990 to 2007 using the regression $\log S N A P_{j t}=\alpha+\beta U_{j t}+$ $\eta_{j}+\varphi_{t}+\varepsilon_{j t}$. We create 20 bins for residual values of $U_{j t}$ and compute conditional means within each bin for SNAP enrollment. Standard errors are clustered by state.

We estimate the impact of unemployment on SNAP enrollment using annual county and state data from 1990 to 2007 . Results shown are for model which weights counties by population (Table 3, column 2). 95\% confidence interval in gray is computed using the delta method. 


\section{FIGURE 8 - Effect of Unemployment and Policy on SNAP Enrollment in the Great Recession}
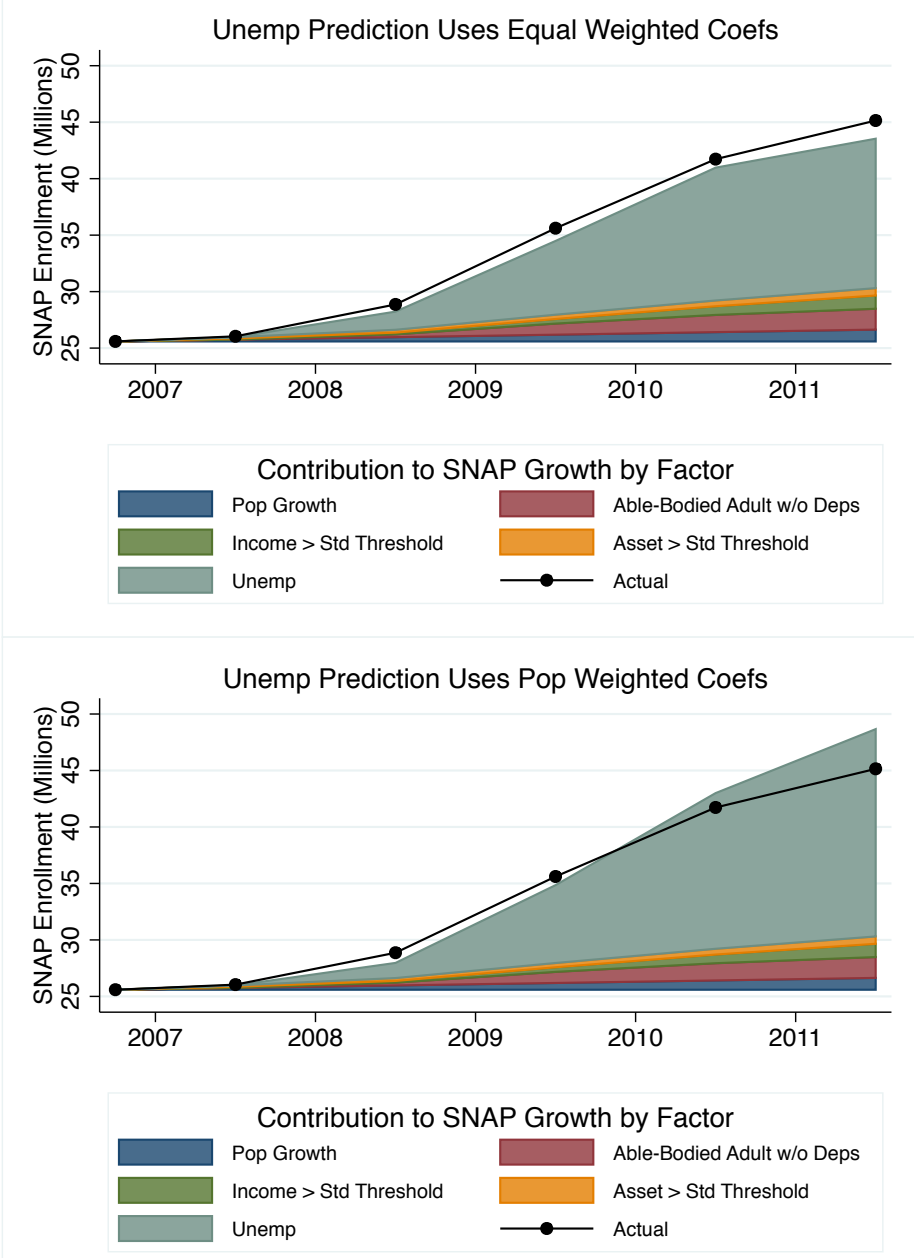

Notes: This figure combines the estimates for the impact of the unemployment rate on SNAP enrollment from Table 3 with the estimates for the impact of eligiblity expansions from Table 4. Table 3 presents two different specifications for the impact of unempoyment on SNAP receipt. The top panel shows results using the specification where each county is equally weighted and the bottom panel using population weights (see Section 5.2 for details). Many states adopted relaxed income and asset thresholds during the recession ("BBCE") and elevated unemployment triggered waivers of time limits for Able Bodied Adults Without Dependents, also known as "ABAWDs" (see Section 5.3 for details). The estimated contribution of these policy changes to overall change in enrollment are the same in the top and bottom panel. 
TABLE 1 - SNAP Enrollment Decomposition, 1993-1999

Sample: Families with Single Mothers

Eligibility Data Source

SNAP Enrollment Data Source

\begin{tabular}{ll} 
Enrollment & (Millions) \\
CPS & CPS \\
QC & CPS \\
\hline
\end{tabular}

Base enrollment of people in single-mom families, 1993

13.07

9.33

(1) Decreased eligibility, w/take-up fixed (inc $>130 \%$ pov)

$-2.18$

$-1.56$

(2) Decreased take-up by eligibles (inc $<=130 \%$ pov)

$-2.24$

$-2.07$

(2a) Changing work and cash assistance patterns

$-2.76$

$-1.34$

(2b) Changing take-up within cell

0.51

$-0.43$

$(1)+(2)$ Total change in SNAP enrollment

$-4.43$

$-3.63$

Note: We use the March Current Population Survey (CPS) together with the SNAP Quality Control (QC) files to study SNAP enrollment by single mothers with children from 1993 through 1999. We develop a unique decomposition of enrollment changes by income eligibility, and among eligibles, by take-up rates separately for families working and families receiving cash assistance.

Eligibility Data We estimate the number of eligible people as those in families with income less than $130 \%$ of poverty in the CPS. We define a family as working it has earned income of at least $25 \%$ of the poverty line and as receiving cash assistance if it reports payments of at least $10 \%$ of the poverty line. We then sub-divide the likely-eligible sample into four groups: 'Work Only', 'Cash Assistance Only', 'Work and Cash', or 'Neither Work Nor Cash'.

SNAP Enrollment Data We estimate the number of people enrolled in each of these four groups using QC data, and separately using CPS data. The QC data come from administrative sources, but use a monthly accounting concept. The CPS data on SNAP receipt cover the prior year, but suffer from underreporting. Appendix Table 1 reports take-up estimates for each of these four subgroups using both methods. 
TABLE 2 - Policies to Increase SNAP Accessibility

\begin{tabular}{llll}
\hline \hline & & & \\
& 2001 & 2007 & 2011 \\
Broad-Based Categorical Eligibility & 7 & 13 & 41 \\
Exclude At Least One Vehicle From Asset Test & 9 & 46 & 49 \\
SSI Combined Application Project & 1 & 12 & 17 \\
Face-to-Face Recertification Interview Waiver & 0 & 22 & 47 \\
Online Application & 0 & 14 & 30 \\
Simplified Reporting & 4 & 47 & 49 \\
Call Center & 7 & 21 & 32 \\
Do Not Certify Earners Every 3 Months & 26 & 50 & 50 \\
& & & .77 \\
Summary Index Mean & .13 & .55 & \\
\hline \hline
\end{tabular}

Source: SNAP Policy Database in July of each year. Vehicle exemptions, simplified reporting, and call centers are missing in 2011, and we use the 2010 values. The summary index is the sum of all the policy indicators, divided by 8. 
TABLE 3 - County-Level SNAP Enrollment and Unemployment, 1990-2007

\begin{tabular}{|c|c|c|}
\hline & $\begin{array}{c}(1) \\
\text { Lor(SNAP Fnrollment) }\end{array}$ & $\begin{array}{c}(2) \\
\text { Log(SNAP Enrollment) }\end{array}$ \\
\hline \multirow{2}{*}{ State Unemployment $_{t}$} & $0.076^{* * *}$ & $0.12^{* * *}$ \\
\hline & $(0.026)$ & $(0.040)$ \\
\hline \multirow{2}{*}{ State Unemployment ${ }_{t-1}$} & 0.018 & -0.013 \\
\hline & $(0.012)$ & $(0.019)$ \\
\hline \multirow[t]{2}{*}{ State Unemployment ${ }_{t-2}$} & -0.0039 & $0.060 *$ \\
\hline & $(0.026)$ & $(0.034)$ \\
\hline \multirow[t]{2}{*}{ County Unemployment ${ }_{t}$} & $0.010^{* *}$ & -0.0057 \\
\hline & $(0.0039)$ & $(0.014)$ \\
\hline \multirow[t]{2}{*}{ County Unemployment $_{t-1}$} & $0.0087^{* * *}$ & $0.015^{* * *}$ \\
\hline & $(0.0024)$ & $(0.0043)$ \\
\hline \multirow[t]{2}{*}{ County Unemployment $_{t-2}$} & 0.0011 & $0.017 * * *$ \\
\hline & $(0.0035)$ & $(0.0059)$ \\
\hline Sum of Coefficients & .11 & .195 \\
\hline Weights & Equal & Population \\
\hline County Fixed Effects & Yes & Yes \\
\hline Year Fixed Effects & Yes & Yes \\
\hline Sample & \multicolumn{2}{|c|}{ 1990-2007 } \\
\hline$R^{2}$ & 0.97 & 0.96 \\
\hline Observations & 42169 & 42169 \\
\hline
\end{tabular}

Notes: SNAP enrollment is available for about 2,700 counties each July. Standard errors clustered by state. ${ }^{*} \mathrm{p}<0.1,{ }^{* *} \mathrm{p}<0.05,{ }^{* * *} \mathrm{p}<0.01$ 


\section{TABLE 4 - SNAP Enrollment and Eligibility Changes}

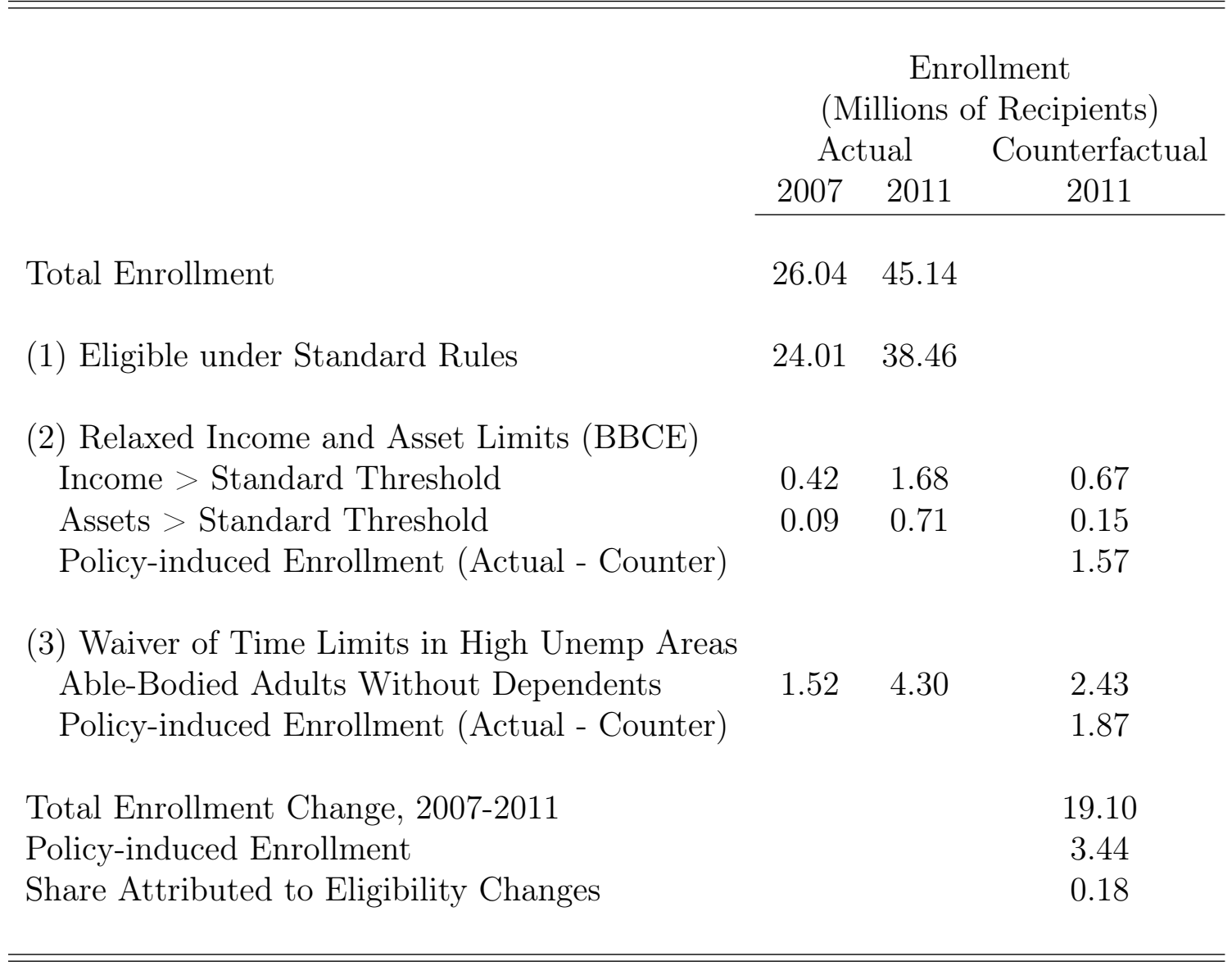

Note: Enrollment counts are average monthly caseload for Q3 in QC files. Both ABAWD waivers and state BBCE adoption expanded from 2007 to 2011. We calculate a no-eligibilitychange counterfactual by assuming that enrollment for these groups grew at the same rate as enrollment for people eligible under standard rules.

Relaxed Income and Asset Limits through Broad-Based Categorical Eligibility (BBCE). In 2007, 13 states had adopted some version of BBCE, and by 2011, 41 states had BBCE. Using the QC files, we estimate the number of households as which are eligible only due to relaxed income limits. See text for details. The QC files lack data to adequately evaluate assets. Idaho and Michigan re-introduced asset limits of $\$ 5,000$ in 2011 , and about $1 \%$ of cases were closed due to excess assets (GAO 2012). Using the Survey of Consumer Finances, we estimate that asset limits of $\$ 2,000$ would have caused caseloads to fall by $2 \%$. In 2007 , the 11 states without asset tests accounted for $18 \%$ of SNAP enrollment and in 2011, the 39 states without asset tests in 2011 accounted for $79 \%$ of total SNAP enrollment.

Waiver of Time Limits for Able-Bodied Adults Without Dependents (ABAWDs) Under standard program rules, there is a 3-month time limit on SNAP receipt for ABAWDs who are not working full time and not participating in an employment training program. See text for details. 
TABLE 5 - Comparison with Mulligan (2012), by Policy

\begin{tabular}{lcc}
\hline \hline & & \\
& & \\
Relaxed Venrollment 2007-2011
\end{tabular}




\section{A Data Appendix}

\section{A.1 Survey of Income and Program Participation}

We use the Survey of Income and Program Participation (SIPP) to analyze familylevel unemployment and SNAP receipt in 2007 and 2011. The unit of observation is always a person, with cross-sectional person weights (wpfinwgt). We observe enrollment in cash assistance and SNAP at the individual level. We assign all individuals in the same family the same status for potential SNAP eligibility (family income $<$ $130 \%$ of poverty), unemployment, and family earnings.

\section{A.1.1 Family-Level Data on Unemployment and SNAP}

We use waves 8-11 of the 2004 SIPP and waves 6-9 of the 2008 SIPP. We use family definitions which include subfamilies as part of the same unit (rfid) from month 4 of the final wave of the analysis sample.

Unemployment We construct a person-level measure of unemployment over the previous four waves. The SIPP records weekly labor force status for people age 15 or higher. Of people in this age group in wave 11 of the 2004 panel and wave 9 of the 2008 SIPP, a complete retrospective sixteen-month history is available for about $81 \%$ of people. We compute an individual's unemployment status using all available months, including those individuals for whom data on some months is missing. We compute the unemployment rate as the number of weeks unemployed (rmwklkg), divided by the number of weeks the person was in the labor force (rmwklkg + rmwkwjb). We aggregate this measure to the family level by taking a simple average of unemployment rates across family members.

SNAP Receipt We use self-reported SNAP receipt rcutyp27 (ignoring observations where SNAP receipt is allocated, a27amt) from the fourth reference month, which is the month preceding the interview. Meyer et al. (2009) document underreporting of transfer program receipt in household surveys. In wave 11 of the 2004 SIPP, which covers SNAP receipt from July to October 2007, $6.3 \%$ of people report receiving SNAP, while administrative data show that the average monthly caseload was $8.9 \%$. In wave 9 of the 2008 SIPP, which covers SNAP receipt from April to July $2011,9.8 \%$ of people report receiving SNAP, while administrative data show that the average monthly caseload was $14.5 \%$. Meyer and Goerge (2011) link administrative data on SNAP receipt to the ACS and CPS. They find that the false negative rate (report no SNAP receipt in survey when admin records do show SNAP receipt) is much higher than the the false positive rate.

Formally, we want to know the relationship between unemployment duration $U$ and SNAP receipt. If there are only false negatives, then $\operatorname{Pr}($ ReportSNAP ReceiveSNAP $)=$ $71 \%$ in 2007 and $68 \%$ in 2011 . To match administrative totals, we recode each personlevel indicator of SNAP receipt to 1.41 in the 2007 sample and 1.48 in the 2011 sample. Formally, such a modification is equivalent to assuming $\operatorname{Pr}(\operatorname{Report} S N A P \mid \operatorname{ReceiveSNAP,U)}$ 
is equal for all $U$. Intuitively, it says that peope with long unemployment durations are as likely to underreport SNAP receipt as people with short unemployment durations. Meyer and Goerge (2011) estimate the relationship between unemployment status and the false negative rate (report no SNAP receipt when admin records do show SNAP receipt) in the CPS and ACS. In three out of four specifications they find no statistically significant relationship. In the fourth, they find that the false negative rate is higher for people who are unemployed; if this is true, then our method understates the strength of the relationship between unemployment and SNAP receipt.

\section{A.2 Area-Level Data on Unemployment and SNAP}

We link data from the Local Area Unemployment Statistics (LAUS) series published by the Bureau of Labor Statistics to administrative data on SNAP enrollment from the Food and Nutrition Service (FNS) at USDA.

SNAP Enrollment State SNAP offices report monthly enrollment to FNS at the project level each January and July. We use the July data from the fifty states plus DC. States have discretion over the geographic definition of "project." Many states report enrollment at each SNAP office with a 7-digit id of which the first 5 digits are a county FIPS code. We collapse the data to the county level using 5-digit FIPS codes. AK, CT, ME, MA, NH, OR, RI, UT, VT, WV, and WY never report countylevel enrollment. NY and ID stop reporting county-level enrollment in January 1992. We drop all these states from the sample. Missouri stops county-level reporting in 2007, Nebraska stops in 1994, and Montana stops in 2002; for these states, we use county data in the years it is available.

We drop tribal geographies in Minnesota and Arizona. We drop 12 county-year pairs where enrollment exceeds county population, and another 16 county-year pairs where enrollment jumps to at least $40 \%$ of the population for one year and then immediately falls again.

In 1990, we have county-level data for $85 \%$ of SNAP enrollment in our cleaned sample, and by 2007, after some states have stopped reporting, we have county-level data for $80 \%$ of SNAP enrollment.

Unemployment LAUS estimates monthly state-level and county-level unemployment rates. The state-level estimates are controlled to match results from the Current Population Survey (CPS). Because the CPS samples relatively few households per state (from about 800 per month in Mississippi to about 4,300 per month in California), and the unemployment rate typically varies from around $5 \%$ to $10 \%$, it is quite difficult to precisely estimate state unemployment rates, especially in small states. LAUS then uses administrative data on the place of residence of unemployment insurance recipients to allocate the CPS-based state unemployment estimates county-by-county. See http://www.bls.gov/lau/laumthd.htm for details on estimation methodology. We use flat files from 1990-2012 posted 
at ftp://ftp.bls.gov/pub/time.series/la/. For about 500 county geographies labeled with series_id "PA" or "PS", LAUS reports a geographic identifier which is not a valid 5-digit county FIPS code. We use data from http://www.bls.gov/lau/laucnty12.xls to crosswalk these LAUS geographies to county FIPS codes. We observe July SNAP enrollment in year $t$, and we construct annual unemployment in year $t$ using data from the preceding 12 months (the average unemployment rate from July in year $t-1$ to June in year $t$ ).

Population We use annual population estimates from the Census Bureau posted at http://www.census.gov/support/USACdataDownloads.html

Merged County Data We merge the county-level datasets using year and 5-digit FIPS codes. Every observation in the unemployment dataset also appears in the population dataset. There are 7 fips codes from FNS that do not match the county unemployment file; they account for $0.01 \%$ of enrollment. We have 47,940 observations between 1990 and 2007 with nonmissing, positive SNAP enrollment and a county-level estimate of the unemployment rate. Our analysis sample has 42,169 observations, because we require two lags of the local unemployment rate. 


\section{APPENDIX FIGURE 1 - SNAP Entrance and Exit Rates}

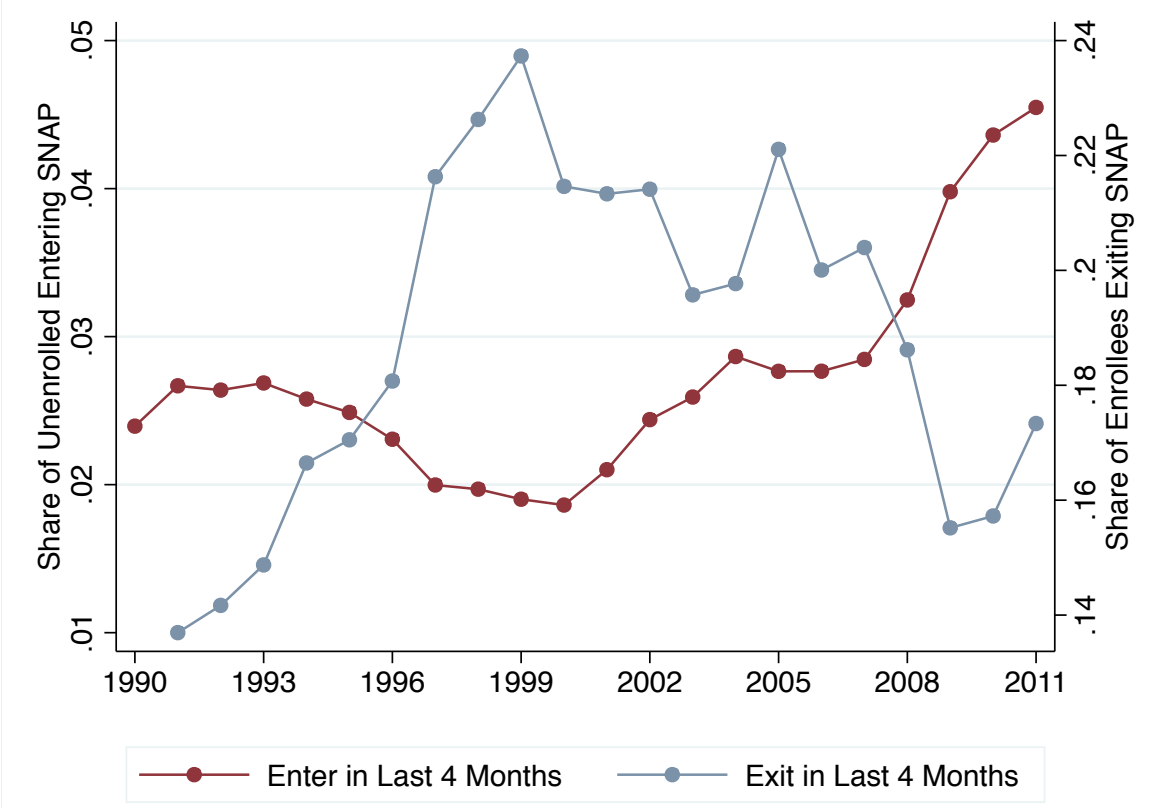

Notes: We construct an indicator for whether someone entered SNAP in last 3 months using the SNAP QC files. We estimate exit $_{t}=$ stay $_{t-1}+$ entrant $_{t-1}-$ stayt $_{t}$. EntryRate $_{t}=$ enter $_{t} /\left(\right.$ pop $\left.\left._{t}-S N A P_{t}\right)\right)$ and ExitRate Ex $=$ exit $_{t} / S N A P_{t}$. See Section 3 for details. 


\section{APPENDIX TABLE 1 - SNAP Enrollment Decomposition,} 1993-1999

\begin{tabular}{ccccccc} 
Panel A: CPS Denominator & \multicolumn{4}{c}{ Shares Among Inc $\leq 130 \%$ Pov } \\
\cline { 3 - 6 } & N (millions) & Inc $\leq 130 \%$ Pov & Work Only & Cash Only & Work \& Cash & Neither \\
1993 & 21.19 & 0.63 & 0.29 & 0.42 & 0.05 & 0.24 \\
1994 & 21.67 & 0.61 & 0.30 & 0.42 & 0.05 & 0.23 \\
1995 & 21.85 & 0.59 & 0.32 & 0.39 & 0.06 & 0.23 \\
1996 & 22.02 & 0.58 & 0.33 & 0.37 & 0.07 & 0.23 \\
1997 & 21.84 & 0.58 & 0.34 & 0.33 & 0.07 & 0.27 \\
1998 & 22.19 & 0.56 & 0.41 & 0.26 & 0.07 & 0.27 \\
1999 & 21.31 & 0.53 & 0.45 & 0.19 & 0.06 & 0.30
\end{tabular}

\begin{tabular}{ccccccc}
\multirow{2}{*}{ Panel B: SNAP QC Numerator } & & \multicolumn{3}{c}{ Ratio Within Cell: QC SNAP / CPS Elig } \\
\cline { 4 - 7 } & N (millions) & Ratio: SNAP/Elig & Work Only & Cash Only & Work \& Cash & Neither \\
1993 & 13.07 & 0.97 & 0.48 & 1.57 & 0.84 & 0.54 \\
1994 & 13.12 & 0.99 & 0.48 & 1.57 & 0.97 & 0.56 \\
1995 & 12.61 & 0.99 & 0.51 & 1.64 & 0.78 & 0.61 \\
1996 & 12.19 & 0.95 & 0.50 & 1.54 & 0.81 & 0.69 \\
1997 & 10.74 & 0.84 & 0.53 & 1.40 & 0.84 & 0.53 \\
1998 & 9.45 & 0.76 & 0.46 & 1.34 & 1.07 & 0.57 \\
1999 & 8.64 & 0.77 & 0.45 & 1.65 & 1.15 & 0.62
\end{tabular}

\begin{tabular}{ccccccc}
\multirow{2}{*}{ Panel C: } & SNAP CPS Numerator & & \multicolumn{4}{c}{ Ratio Within Cell: CPS SNAP / CPS Elig } \\
\cline { 5 - 7 } & N (millions) & Ratio: SNAP/Elig & Work Only & Cash Only & Work \& Cash & Neither \\
1993 & 9.33 & 0.69 & 0.38 & 0.96 & 0.90 & 0.52 \\
1994 & 9.20 & 0.69 & 0.44 & 0.96 & 0.85 & 0.55 \\
1995 & 8.40 & 0.66 & 0.40 & 0.95 & 0.86 & 0.53 \\
1996 & 8.22 & 0.64 & 0.40 & 0.96 & 0.89 & 0.51 \\
1997 & 7.66 & 0.60 & 0.36 & 0.97 & 0.93 & 0.50 \\
1998 & 7.03 & 0.57 & 0.37 & 0.93 & 0.92 & 0.50 \\
1999 & 5.70 & 0.51 & 0.34 & 0.95 & 0.83 & 0.48
\end{tabular}

\footnotetext{
Note: We use the March Current Population Survey (CPS) together with the SNAP Quality Control (QC) files to study SNAP enrollment by single mothers with children from 1993 through 1999. We develop a unique decomposition of enrollment changes by eligibility by take-up rates, and by take-up rates separately for families working and families receiving cash assistance.

Eligibility Data We estimate the number of eligible people as those in families with income less than $130 \%$ of poverty in the CPS. We define a family as working if it has earned income of at least $25 \%$ of the poverty line and as receiving cash assistance if it reports payments of at least $10 \%$ of the poverty line. We then sub-divide the likely-eligible sample into four groups: 'Work Only', 'Cash Assistance Only' 'Work and Cash', or 'Neither Work Nor Cash'. SNAP Enrollment Data We estimate the ritmber of people enrolled in each of these four groups using QC data, and separately using CPS data.
} 


\section{APPENDIX TABLE 2 - Policy Changes, Take-up and Enrollment}

Dependent Variable

Dependent Variable Mean

(1) Broad-Based Categorical Eligibility

(2) Exclude $>=1$ Vehicle From Asset Test

(i) Eligibility Index $[(1)+(2)] / 2$

(3) SSI Combined Application Project

(4) Face-to-Face Recert Interview Waiver

(5) Online Application

(ii) Enrollment Index $[(3)+(4)+(5)] / 3$

(6) Simplified Reporting

(7) Call Center

(8) No 3-Month Earner Recerts

(iii) Stay Enrolled Index $[(6)+(7)+(8)] / 3$

Summary Index [Sum of (1) to (8)] / 8

State Fixed Effects

Year Fixed Effects

Sample

$\mathrm{n}$

$\begin{array}{cc}\text { Take-Up } & \text { Percent of } \\ \text { Rate } & \text { Pop on SNAP } \\ 65.2 & 9.0\end{array}$

(2)

$\begin{array}{cc}2.41 & 0.72^{* *} \\ (1.56) & (0.29) \\ -0.92 & 0.12 \\ (1.11) & (0.32) \\ 1.24 & 0.77^{* *}\end{array}$

(1.67)

$1.61 \quad 0.40$

(1.76)

1.77

$(0.33)$

(1.18)

0.40

$(0.28)$

$-0.48$

(1.74)

1.89

$-0.07$

$(0.33)$

0.42

$(2.54)$

$3.06^{* *}$

(1.37)

1.80

(1.62)

4.23***

(1.26)

$7.98^{* * *}$

(2.49)

$9.10^{* *}$

(0.49)

$0.72^{* *}$

(0.33)

$0.55^{*}$

(0.31)

$1.01^{* * *}$

(0.28)

$2.00^{* * *}$

(0.50)

$2.51^{* * *}$

(0.63)

$\begin{array}{cc}\text { Yes } & \text { Yes } \\ \text { Yes } & \text { Yes } \\ \text { 1996-2010 } & 1996-2010 \\ 765 & 765\end{array}$

Note: Each cell is a separate regression with a single policy variable, plus state and year fixed effects. Policy data comes from each year's July record in SNAP Policy Database. Take-up rate is the average of all values reported in State Participation Reports (Cunnyngham et al. 2013 is the most recent report). SNAP enroll $m$ ment is for July. States are weighted equally. Standard errors are clustered by state. ${ }^{*} \mathrm{p}<0.1,{ }^{* *} \mathrm{p}<0.05$, *** $\mathrm{p}<0.01$ 


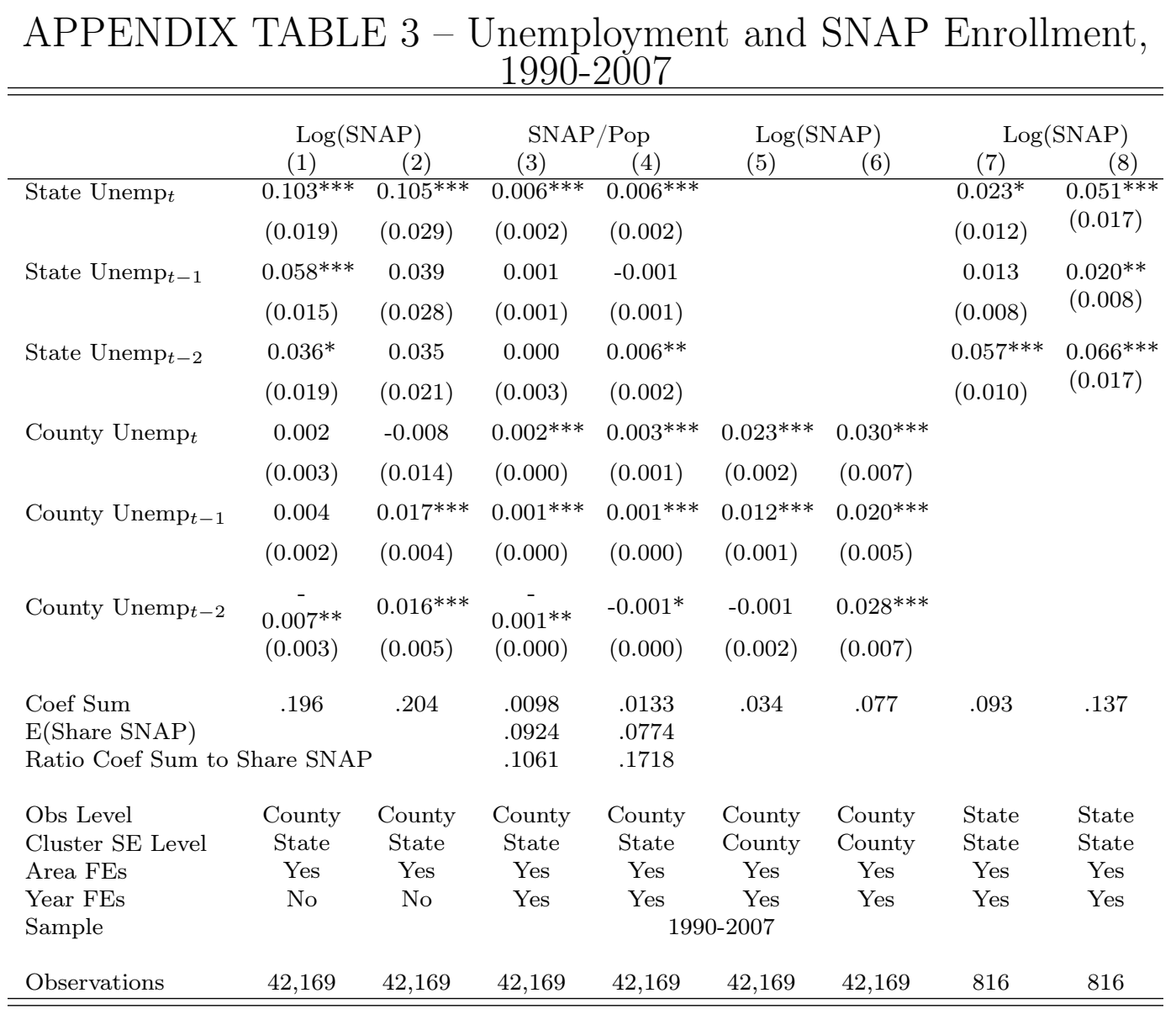

Notes: SNAP enrollment is available for about 2,700 counties each July. Standard errors clustered by state.

${ }^{*} \mathrm{p}<0.1,{ }^{* *} \mathrm{p}<0.05,{ }^{* * *} \mathrm{p}<0.01$ 
APPENDIX TABLE 4 - SNAP Benefits and Eligibility Changes

Spending (Billions of 2011 \$)

Actual Counterfactual

$2007 \quad 2011 \quad 2011$

Total Spending

(1) Eligible under Standard Rules

(2) Relaxed Income and Asset Limits (BBCE)

Income $>$ Standard Threshold

Assets $>$ Standard Threshold

Policy-induced Spending (Actual - Counter)
$31.94 \quad 71.94$

$28.91 \quad 60.90$

$0.22 \quad 0.65$

0.46

$0.11 \quad 1.14$

0.24

1.08

$2.70 \quad 9.25$

5.68

3.57

Policy-induced Spending (Actual - Counter)
40.01

4.66

0.12

Note: Projected annual spending based on Q3 data. See notes to Table 4 for explanation of categories. We assume that recipients with excess assets receive on average the same benefits as other households. This likely overstates the amount of benefits paid to these households. 